\title{
Development and Application of Rapid Injection Molds Using Aluminum-Filled Epoxy Resins for Metal Injection Molding
}

Chil-Chyuan Kuo ( jacksonk@mail.mcut.edu.tw)

Ming Chi University of Technology https://orcid.org/0000-0003-0519-4126

Xin-Yu Pan

Department of Mechanical Engineering, Ming Chi University of Technology

Cheng-Xuan Tasi

Department of Mechanical Engineering, Ming Chi University of Technology

\section{Research Article}

Keywords: Rapid tooling, Metal injection molding, Die life, Manufacturing time, Manufacturing cost

Posted Date: April 14th, 2021

DOl: https://doi.org/10.21203/rs.3.rs-404975/v1

License: (c) (i) This work is licensed under a Creative Commons Attribution 4.0 International License.

Read Full License 


\section{Abstract}

Metal injection molding (MIM) is a near net-shape manufacturing process combing conventional plastic injection molding and powder metallurgy. Two kinds of injections molds for MIM were developed using conventional mold steel and aluminum (Al)-filled epoxy resins in this study. The characteristics of the mold made by rapid tooling technology (RTT) were evaluated and compared to that fabricated conventional machining method through MIM process. It was found that the service life of the injection mold fabricated by Al-filled epoxy resins is about 1300 molding cycles. The saving in manufacturing cost of an injection mold made by Al-filled epoxy resins is about $30.4 \%$ compared to that fabricated conventional mold steel. The saving in manufacturing time of an injection mold made by RT technology is about $30.3 \%$ compared to that fabricated conventional machining method.

\section{Introduction}

Metal injection molding (MIM) is a near-net shape manufacturing approach for fabricating metal components with excellent mechanical properties [1, 2]. In addition, the powder injection molding (PIM) offers a unique solution for the mass production of precision parts with excellent mechanical properties. The advantages of MIM involve high production rate, good mechanical properties, good dimensional control, and good shape complexity. The disadvantages include high sintering temperature, part size limitation, and product with residual pores. The powders used for MIM or PIM involve zirconia [3], $316 \mathrm{~L}$ stainless steel $[4,5]$, tungsten carbide [6, 7], titanium [8, 9], copper, chrome steel, and nickel. In general, the MIM process consists of four distinct steps, i.e. mixing, injection molding, debinding, and sintering. Firstly, the metallic powders were mixed with binders to form a feedstock. The feedstock was then injected to cavity for manufacturing green parts using MIM machine. The binder of green parts can be removed by the de-binding process to form brown parts. Finally, brown parts were sintered at a high temperature and in a high vacuum atmosphere to form final parts. Some studies regarding the MIM process have been carried out. Safarian et al. [10] investigated the effects of sintering parameters, such as dwell time, sintering temperature, and heating rate on diffusion bonding of $316 \mathrm{~L}$ stainless steel in inserted metal injection molding. It was found that the sintering temperature is the most important parameter compared to the dwelling time and heating rate on diffusion bonding of 316 stainless steel. Sahli et al. [11] developed a numerical model based on elastic-viscoplastic constitutive equations for calculating macroscopic deformation and structural evolution during sintering of complex micro-gear compacts. Hayat et al. [12] developed water-soluble PEG/PMMA binder systems for $\mu$-MIM. It was found that the developed binder systems are more suitable for $\mu$-MIM process that has an inherently higher cooling rate. Imgrund et al. [13] proposed two-component metal injection molding for manufacturing of multifunctional micro parts. It was found that intact material interfaces of less than $500 \mu \mathrm{m} \times 500 \mu \mathrm{m}$ can be obtained by careful selection and tailoring of metal powders, injection molding and co-sintering parameters. Oh et al. [14] investigated the nano powder effects on both of solvent and thermal debinding processes. The results showed that the immersing time requiring in the solvent was increased by the nano powder and the amount of the residual binder. Kate et al. [15] investigated the influence of 
feedstock properties on the injection molding of aluminum nitride. It was found that the estimated feedstock properties as input parameters in mold-filling simulations that could be extended for a variety of material systems and geometries early in the design phase. Lamarre et al. [16] developed a new injection concept for increasing the moldability of powder-binder mixtures in the low-pressure powder injection molding. Zhang et al. [17] used three metallic powders with different compositions, particle shapes and particle sizes for producing micro-structured parts using injection molding process. The results showed that the micro-structured parts can be obtained using the process chain of injection, debinding and sintering with metallic powders. Zhang et al. [18] produced the $\mathrm{M} 2$ tool steel components with microstructures using PIM process. Nayak et al. [19] developed powders to fabricate stainless steel parts using PIM process. García et al. [20] fabricated steel matrix composites reinforced with different amounts of vanadium carbide (VC) using MIM process and investigated the effects of adding VC on dry sliding wear behavior using both pin-on-disk and ball-on-flat tests. Dehghan-Manshadi et al. [21] reviewed recent developments in MIM of titanium and its alloys as well as the outstanding challenges with a special focus on MIM of hydride-dehydride titanium powder. Thavanayagam et al. [22] investigated the effect of binder composition, powder loading, de-binding time and temperature on the debinding rate for removing polyethylene glycol-polyvinyl butyral with water, and porosity and microstructure of molded parts. Two materials have been proposed for fabricating mold inserts for MIM process, including silicone [23] and hardened steel [24]. However, these methods have disadvantages, including complex manufacturing processes, long processing time, and high production cost. Inductively-coupled plasma etching requires high production cost due to the complex manufacturing processes and long processing time. In addition, conventional milling machine has limitations on the minimum size of the microstructures in mold insert. To solve these drawbacks, a cost-effective method for fabricating an injection mold for MIM process was demonstrated using rapid tooling technology (RTT) [25-30]. In this study, injection molding simulation software Modlex3D was employed to determine the initial process parameter settings for MIM. The Al-filled epoxy resins were used to fabricate injection mold using RTT and applied to MIM. The characteristics of the injection mold fabricated by RTT were evaluated and compared to that fabricated conventional machining method through MIM process. The changes in surface roughness of the mold surface after MIM were continuously recorded to evaluate the longevity of the injection molds fabricated. The difference between mold life, production cost and production time was investigated.

\section{Experimental Details}

A manufacturing process for fabricating an injection mold for MIM process was developed. Figure 1 shows the process layouts for fabricating an ultra-large injection mold with complex geometric conformal cooling channels. An intermediary mold which is complementary in shape to the injection mold was fabricated by both liquid silicone rubber (KE-1310ST, Shin Etsu Inc.). The Al-filled epoxy resins (TE 375, Jasdi Chemicals Inc.) was used to make an injection mold through the intermediary mold. A vacuum machine (F-600, Feiling) was used to eliminate air bubbles from the resulting mixture. The fabricated injection mold was then cured using a convection oven (DH400, Deng Yag Inc.) for obtaining the required 
mechanical properties. Finally, the fabricated injection mold was machined to the dimensions needed. In order to compare the performance of the injection molds fabricated by Al-filled epoxy resins, STAVAXelectro slag remelting (ESR) stainless mold steel (ASSAB Inc.) was also used to fabricate an injection mold. An injection machine (a-S100iA, FANUC Inc.) was used to form green parts. In this study, two-plate mold with a direct gate was used in this study because it is the easiest injection mold structure. In addition, two cavities in one mold base were used in this study because the performance of two different mold inserts can be evaluated under the same injection process parameters. Table 1 shows the MIM process parameters. The master model and injection mold were designed by using Pro/ENGINEER software. The dimensions of the master model were $15 \mathrm{~mm}$ in length, $15 \mathrm{~mm}$ in width, and $2 \mathrm{~mm}$ in thickness. The feedstock is the mixture of metal powder and binder for injection molding. The quality of feedstock is depended on the type of metal powder and binder because the agglomeration, debinding, particle packing, and dimensional correctness were affected by the type of binder employed. In this study, the metal matrix composite contains Fe and Ni powers. The polypropylene and paraffin wax in a proportion of 50:50 were mixed as binder in this study. The metal powders (60 vol. \%) and binder (40 vol. $\%$ ) were warmed at $100^{\circ} \mathrm{C}$ and then mixed in a mixer at $150^{\circ} \mathrm{C}$ for $2 \mathrm{~h}$. The average particle sizes of the metal powders were examined by field emission scanning electron microscopy (SEM) (JEC3000-FC, JEOL Inc.). The solvent (n-Heptane) de-binding process was used to remove the binder from the green parts. The solvent debinding time was about $6 \mathrm{~h}$ using a de-wax furnace (MIM-500D, Yu-He Inc.). The sintered products can be obtained from green parts using a vacuum sintering furnace (VM-600, Mei-Yang Inc.). The sintering temperature was about $1300^{\circ} \mathrm{C}$ with a heating rate of $5-10^{\circ} \mathrm{C} / \mathrm{min}$ under nitrogen purged atmosphere. The sintering time was about $24 \mathrm{~h}$ in the vacuum environment. In order to minimize the defects caused by the nature of injection molding process, Moldex 3D simulation software was used in this study because it provides the quality control tool for evaluating molding conditions. The service life of the two kinds of injection molds were carried out using an MIM injection machine. The centre-line average surface roughness $(\mathrm{Ra})$ value was used to evaluate the changes in the surface roughness of the two kinds of injection molds. The measuring range is $250 \mu \mathrm{m} \times 250 \mu \mathrm{m}$. The WLI (7502, Chroma Inc.) was used to measure the surface roughness of the mold surface after MIM. The changes in surface roughness of the fabricated injection mold were investigated and compared to the injection mold fabricated by conventional mold steel. The micro-Vickers hardness of specimens was measured under the load of $2.9 \mathrm{~N}$ with $15 \mathrm{~s}$ using a micro-Vickers hardness tester (HM-112, Mitutoyo Akashi Inc.). Typical defects in the sintered parts such as porosity, cavities, inclusions and cracks were examined via an X-ray computed tomography (CT) scan (Tom tomoscope 200 - 190 3D CNC Werth Messtechnik GmbH Inc.). 
Table 1

MIM process parameters

\begin{tabular}{|ll|}
\hline Parameters & Value \\
\hline Injection time $(\mathrm{s})$ & 0.108 \\
\hline Injection pressure $(\mathrm{MPa})$ & 70 \\
\hline Injection speed $(\mathrm{mm} / \mathrm{s})$ & 80 \\
\hline Packing pressure $(\mathrm{MPa})$ & 50 \\
\hline Packing time $(\mathrm{s})$ & 1 \\
\hline Molding temperature $\left({ }^{\circ} \mathrm{C}\right)$ & 160 \\
\hline Mold temperature $\left({ }^{\circ} \mathrm{C}\right)$ & 20 \\
\hline
\end{tabular}

\section{Results And Discussion}

The metal injection molding simulation software Moldex 3D can be resolved and predicted the metal injection molding problems in the mold design stage. In this study, an injection mold with two cavities was designed for MIM process, as shown in Figure 2. Figure 3 shows the simulation result of filling process. The filling time of the molded part is approximately $0.108 \mathrm{~s}$. Figure 4 shows the simulation result of maximum injection pressure. The maximum injection pressure is approximately $59.72 \mathrm{MPa}$. In general, the powder concentration distribution is usually unsteady. Figure 5 shows the simulation result of the powder concentration distribution. As can be seen, black-line marks were observed near the gate due to low powder concentration. Figure 6 shows the simulation result of volume shrinkage. The shrinkage of molded part is uniform and the volume shrinkage is approximately $2.36 \%$ [31]. Figure 7 shows the simulation result of the warpage. As can be seen, the molded part was deformed inward and the total displacement of the warpage is approximately $0.034 \mathrm{~mm}$.

Figure 8 shows the morphology of the Fe powder. Figure 9 shows the morphology of the Ni powder. Figure 10 show the results of the short shot test. As can be seen, the whole filling processes of the green part were similar to the simulation results [32]. Figure 11 shows the injection molds fabricated by rapid tooling and STAVAX steel. Figure 12 shows a green part was ejected during MIM process. Figure 13 shows the green parts fabricated by STAVAX steel and Al-filled epoxy rapid tooling via MIM process. The length, width and thickness of the molded part are $15 \mathrm{~mm}, 15 \mathrm{~mm}$ and $2 \mathrm{~mm}$, respectively. In order to make the green parts easily release from the mold inserts, the draft angle of the molded part was designed as $5^{\circ}$. This result shows that the green part of Fe2Ni can be successfully fabricated by an injection mold fabricated by Al-filled epoxy rapid tooling.

In order to evaluate the longevity of injection molds made by STAVAX stainless steel [33] and Al-filled epoxy resins, the MIM process was carried out with feedstock of Fe2Ni. Figure 14 shows the average surface roughness of mold surface as a function of injection molding cycles. Figure 15 shows the 
average surface roughness of the injection mold fabricated by STAVAX stainless steel after 1 to 2500 injection molding cycles. As can be seen, the average surface roughness of mold fabricated by STAVAX stainless steel after 1, 500, 900, 1300, 1600, 2500, and 2700 molding cycles were $148 \mathrm{~nm}, 168 \mathrm{~nm}, 156$ $\mathrm{nm}, 160 \mathrm{~nm}, 147 \mathrm{~nm}, 212 \mathrm{~nm}$, and $143 \mathrm{~nm}$, respectively. Figure 16 shows the average surface roughness of the injection mold fabricated by Al-filled epoxy resins after 1 to 2500 injection molding cycles. The average surface roughness of the injection mold fabricated by Al-filled epoxy resins after 1, 500, 900, 1300, 1600, 2500, and 2700 molding cycles were 174 nm, 161 nm, 175 nm, 158 nm, 219 nm, 227 nm, and $220 \mathrm{~nm}$, respectively. The results clearly show that the changes in the average surface roughness of the injection mold fabricated by Al-filled epoxy resins before 1300 molding cycles is very close to that of the injection mold fabricated by STAVAX stainless steel. However, the average surface roughness of the injection mold fabricated by Al-filled epoxy resins increased with increasing the injection mold cycles after 1300 molding cycles.

To understand the dimensional accuracy of the green parts molded by mold steel and injection molding tool, a series of experiments was performed [34]. Figure 17 shows the dimension of the green part as a function of injection molding cycles. As can be seen, the dimension of the green part increased abruptly after 1300 injection molding cycles, while the changes in the dimension of the green part were stabilized after injection molding cycles of 2,000. The dimension of the green part fabricated by the mold made of STAVAX stainless steel after 1, 500, 900, 1300, 1600, 2500, and 2700 molding cycles was $14.6 \mathrm{~mm}, 14.57$ $\mathrm{mm}, 14.58 \mathrm{~mm}, 14.66 \mathrm{~mm}, 14.65 \mathrm{~mm}, 14.66 \mathrm{~mm}$, and $14.66 \mathrm{~mm}$, respectively. The increase in the dimension of the green part was about $0.06 \mathrm{~mm}$ due to the wear of the mold surface after MIM process. The dimension of the green part fabricated by the mold made of Al-filled epoxy resins after 1,500,900, $1300,1600,2500$, and 2700 molding cycles was $14.64 \mathrm{~mm}, 14.64 \mathrm{~mm}, 14.64 \mathrm{~mm}, 14.67 \mathrm{~mm}, 14.68 \mathrm{~mm}$, $14.7 \mathrm{~mm}$, and $14.7 \mathrm{~mm}$, respectively. The increase in the dimension of the green part was also about 0.06 $\mathrm{mm}$ due to the wear on the mold surface after MIM process [35]. According to the changes in both dimension and surface roughness, it was found that the longevity of the injection mold fabricated by Alfilled epoxy resins are about 1300 molding cycles.

To understand the difference in hardness [36] between black-line area and general area in the sintered part, a series of experiments was performed. Figure 18 shows the micro-Vickers hardness of black-line area and general area in the sintered part. The average micro-Vickers hardness of the black-line area is about $162.9 \mathrm{HV}$, while the average micro-Vickers hardness of the general area is only about $149.6 \mathrm{HV}$. As can be seen, the average micro-Vickers hardness of the black-line is higher than those of the general area. This is because the metal powder near the sprue has a higher density than general area due to high injection pressure during MIM.

The final part made with Fe2Ni powders can be applied to the rotating shaft. Figure 19 shows the results of green part and sintered part. The shrinkage of length, width, and thickness of the final part is about $22 \%$. In order to evaluate the advantages of an injection mold fabricated by RT technology, both production costs and manufacturing time of an injection mold fabricated by two different methods were investigated. Figure 20 shows the X-ray analysis of the green part and sintered product. The results 
clearly show that no any defects were found in the green part. However, some defects were found in the sintered products. This is because the defects cannot be fully verified due to polymer materials existed in the green part will affect the inspection results. Therefore, the quality assurance operations of the MIM products still depend on final sintered products. Figure 21 shows the black-line position in the simulation result, green part, and sintered part. It should be noted that the black-line position in both simulation result and green part is in the vicinity of the gate. In addition, the position of black-line position predicted by simulation software is very close to the position of the green parts. This means Moldex 3D simulation solution can effectively predict the position of black-line in the new MIM product development stage. Figure 22 shows the volumetric shrinkage in simulation result and green part. It is interesting to note that there is obvious volumetric shrinkage in the vicinity of the gate. In addition, the volumetric shrinkage position predicted by simulation software is very close to the sintered part.

Figure 23 shows the production cost of the molds fabricated by conventional method and RT technology. The total production cost of an injection mold fabricated by conventional method is about NT\$13,550. The total production cost includes the mold material cost of NT\$600, micro-hole machining cost of NT\$ 150 , wire-cut machining cost of NT\$900, computer numerical control (CNC) machining cost of NT\$ 3,600 , precision milling cost of NT\$300, and mirror finish machining cost of NT\$8,000. The total production cost of an injection mold fabricated by RT technology is only about NT\$9,430. The total production cost involves the mold material cost of NT\$1830, the labor cost of NT\$4,000, CNC machining cost of NT\$3,240, and precision drilling cost of NT\$360. Thus, the saving in production cost of an injection mold made by Al-filled epoxy resins is about $30.4 \%$ compared to that fabricated conventional mold steel. Figure 24 shows the manufacturing time of the molds fabricated by conventional method and RT technology. The total manufacturing time of an injection mold fabricated by conventional method is about $76 \mathrm{~h}$. The total manufacturing time include mold material preparation time of $60 \mathrm{~h}$, micro-hole machining time of $0.5 \mathrm{~h}$, wire-cut machining time of $1.5 \mathrm{~h}, \mathrm{CNC}$ machining time of $5 \mathrm{~h}$, precision milling time of $1 \mathrm{~h}$, and mirror finish machining time of $8 \mathrm{~h}$. The total manufacturing time of an injection mold fabricated by RT technology is only $53 \mathrm{~h}$. The total manufacturing time includes mold manufacturing time of $48 \mathrm{~h}, \mathrm{CNC}$ machining time [37, 38] of $4.5 \mathrm{~h}$, and precision drilling time [39] of 0.5 . Thus, the saving in manufacturing time of an injection mold made by RT technology is about $30.3 \%$ compared to that fabricated conventional machining method. These results obtained are very practical and economical for making large-sized molds [40] for MIM process and offer potential for many applications in the MIM industry. However, inherent limitations of injection molding tool fabricated with Al-filled epoxy resins are their low mechanical properties and heat transfer capability compared to STAVAX stainless steel [41]. These limitations can further be improved by adding copper powders [42,43], molybdenum disulfide [44-47], zirconia ceramics [48,49], or silicon nitride ceramics [50-53] particles in the mixture. These issues are currently being investigated and the results will be presented in a later study.

\section{Conclusions}

MIM is a near-net shaping approach for producing metallic parts with high intricate shape and good mechanical properties. Developing a cost-effective method for fabricating an injection mold is one of the 
key problems needed to be resolved in the development of a new metal part. A new metal part can be fabricated by an injection mold fabricated by conventional mold steel. However, it is not an effective way for a new metallic part in the research and development stages due to high production cost and high risk. The metallic components with high density can be fabricated MIM process integrating powder metallurgy and plastic injection molding. The main conclusions from the experimental work in this study are as

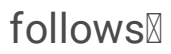

1. The findings of this study are very practical and provide the greatest application potential in the research and development stage of a new metal part.

2. The saving in manufacturing time of an injection mold made by RT technology is about $30.3 \%$ compared to that fabricated conventional machining method.

3. The saving in production cost of an injection mold by Al-filled epoxy resins is about $30.4 \%$ compared to that fabricated conventional mold steel.

4. The longevity of the injection mold fabricated by Al-filled epoxy resins is about 1300 molding cycles.

\section{Declarations}

- Funding:

This study received financial support by the Ministry of Science and Technology of Taiwan under contract nos. MOST 109-2637-E-131-004, MOST 107-2221-E-131-018, MOST 106-2221-E-131-010, MOST 106-2221-E-131-011, and MOST 105-2221-E-131-012.

- Conflicts of interest/Competing interests :Not applicable

- Availability of data and material $\triangle D$ ata and materials are available

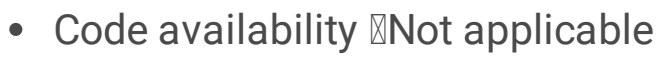

- Authors' contributions $₫$ Arthur $1 \otimes$ Wrote the paper/ Conceived and designed the analysis/ Performed the analysis Arthur 2/3凶 Collected the data/Contributed data or analysis tools

- Ethics approvalखNot applicable

- Consent to participate $\mathbb{I}$ am agreeing to participate

- Consent for publication $\mathbb{\text { I }}$ am agreeing to publish this work

\section{References}

1. Kimura, S. Kadoya, Y. Kajihara," Effects of molding conditions on injection molded direct joining under various surface fine-structuring," The International Journal of Advanced Manufacturing Technology, Volume 101, Issue 9-12, 2019, Page 2703-2712.

2. Park, B. Cha, S. Cho, D. Kim, J. H. Choi, B.-G. Pyo, B. Rhee," A study on the estimation of plastic deformation of metal insert parts in multi-cavity injection molding by injection-structural coupled 
analysis," he International Journal of Advanced Manufacturing Technology, Volume 83, Issue 9-12, 2016, Pages 2057-2069.

3. Liu, X.L. Ni, H.Q. Yin, X.H. Qu, " Mouldability of various zirconia micro gears in micro powder injection moulding," Journal of the European Ceramic Society, Volume 35, Issue 1, 2015, Pages 171-177.

4. M. Attia,J. R. Alcock, " Fabrication of hollow, 3D, micro-scale metallic structures by micro-powder injection moulding," Journal of Materials Processing Technology, Volume 212, Issue 10, 2012, Pages 2148-2153.

5. Belgacem, B. Thierry, G. Jean-Claude, "Investigations on thermal debinding process for fine 316L stainless steel feedstocks and identification of kinetic parameters from coupling experiments and finite element simulations," Powder Technology, Volume 235, 2013, Pages 192-202.

6. Mamen, J. Song, T. Barriere, J.-C. Gelin, “Experimental and numerical analysis of the particle size effect on the densification behaviour of metal injection moulded tungsten parts during sintering," Powder Technology, Volume 270, Part A, 2015, Pages 230-243.

7. Y. Heng, M.R. Raza, N. Muhamad, A.B. Sulong, A. Fayyaz, "Micro-powder injection molding ( $\mu$ PIM) of tungsten carbide," International Journal of Refractory Metals and Hard Materials, Volume 45, 2014, Pages 189-195.

8. Thavanayagam, K.L. Pickering, J.E. Swan, P. Cao , "Analysis of rheological behaviour of titanium feedstocks formulated with a water-soluble binder system for powder injection moulding," Powder Technology, Volume 269, January 2015, Pages 227-232.

9. T. Sidambe, I.A. Figueroa, H.G.C. Hamilton, I. Todd》"Metal injection moulding of CP-Ti components for biomedical applications," Journal of Materials Processing Technology, Volume 212, Issue 7, 2012, Pages 1591-1597.

10. Safarian, M. Subaşi, Ç. Karataş," The effect of sintering parameters on diffusion bonding of 316L stainless steel in inserted metal injection molding," The International Journal of Advanced Manufacturing Technology, Volume 89, Issue 5-8, 2017, Pages 2165-2173.

11. Sahli, A. LebiedJ-C. Gelin,T. Barrière, B. Necib," Numerical simulation and experimental analysis of solid-state sintering response of $316 \mathrm{~L}$ stainless steel micro-parts manufactured by metal injection molding," The International Journal of Advanced Manufacturing Technology, Volume 79, Issue 9-12, 2018, Pages 2079-2092.

12. D. Hayat,T. Li, G. Wen, P. Cao," Suitability of PEG/PMMA-based metal injection moulding feedstock: an experimental study," The International Journal of Advanced Manufacturing Technology, Volume 80, Issue 9-12, 2015, Pages 1665-1671.

13. Imgrund, A. Rota, F. Petzoldt, A. Simchi," Manufacturing of multi-functional micro parts by twocomponent metal injection moulding," The International Journal of Advanced Manufacturing Technology, Volume 33, Issue 1-2, 2007, Pages 176-186.

14. W. Oh, W. S. Lee, S. J. Park," Investigation and modeling of binder removal process in nano/micro bimodal powder injection molding," The International Journal of Advanced Manufacturing Technology, Volume 97, Issue 9-12, 2018, Pages 4115-4126. 
15. H. Kate, R. K. Enneti, S. V. Atre," Influence of feedstock properties on the injection molding of aluminum nitride," The International Journal of Advanced Manufacturing Technology, Volume 90, Issue 9-12, 2017, Pages 2813-2826.

16. G. Lamarre, V. Demers, J.-F. Chatelain," Low-pressure powder injection molding using an innovative injection press concept," The International Journal of Advanced Manufacturing Technology, Volume 91, Issue 5-8, 2017, Pages 2595-2605.

17. Zhang, M. Sahli, J.-C. Gelin, C. Khan-Malek," Experimental analysis of the evolution of the physical properties of pyramidal-shaped metallic replicas made using the MIM process," The International Journal of Advanced Manufacturing Technology, Volume 68, Issue 5-8, 2013, Pages 1063-1074.

18. X. Zhang, M. Chandrasekaran, Q. F. Li, M. K. Ho, M. S. Yong," Studies on the fabrication of tool steel components with micro-features by PIM," The International Journal of Advanced Manufacturing Technology, Volume 38, Issue 3-4, 2008, Pages 278-284.

19. V. Nayak, M. Ramesh, V. Desai, S. K. Samanta," Fabrication of stainless steel based composite by metal injection moulding," Materials Today: Proceedings, Volume 5, Issue 2, Part 2, 2018, Pages 6805-6814.

20. García, F.Martín, G. Herranz, C. Berges, A.Romero,”Effect of adding carbides on dry sliding wear behaviour of steel matrix composites processed by metal injection moulding," Wear,Volumes 414415, 2018, Pages 182-193.

21. Dehghan-Manshadi, M. J. Bermingham, M. S. Dargusch, D. H. StJohn, M. Qian," Metal injection moulding of titanium and titanium alloys: Challenges and recent development," Powder Technology, Volume 319, 2017, Pages 289-301.

22. Thavanayagam, J. E. Swan," Aqueous debinding of polyvinyl butyral based binder system for titanium metal injection moulding," Powder Technology, Volume 326, 2018, Pages 402-410.

23. Liu, X.L. Ni, H.Q. Yin, X.H. Qu," Mouldability of various zirconia micro gears in micro powder injection moulding," Journal of the European Ceramic Society, Volume 35, Issue 1, 2015, Pages 171-177.

24. M. Attia,J. R. Alcock," Fabrication of hollow, 3D, micro-scale metallic structures by micro-powder injection moulding," Journal of Materials Processing Technology, Volume 212, Issue 10, 2012, Pages 2148-2153.

25. Kuo, CC., Zhu, YJ., Wu, YZ. et al. Development and application of a large injection mold with conformal cooling channels. Int J Adv Manuf Technol 103, 689-701 (2019).

26. C. Kuo, Z. Y. You, "Development of injection molding tooling with conformal cooling channels fabricated by optimal process parameters," The International Journal of Advanced Manufacturing Technology, Volume 96, Issue 1-4, 2018, Pages 1003-1013.

27. C. Kuo, S. Y. Lyu, "A cost-effective approach using recycled materials to fabricate micro-hot embossing die for microfabrication," The International Journal of Advanced Manufacturing Technology, Volume 94, Issue 9-12, 2018, Pages 4365-4371.

28. C. Kuo, W. H. Chen, X. Z. Liu, Y. L. Liao, W. J. Chen, B.Y. Huang, R. L. Tsai,” Development of a low-cost wax injection mold with high cooling efficiency," The International Journal of Advanced 
Manufacturing Technology, Volume 93, Issue 5-8, 2017, Pages 2081-2088.

29. C. Kuo, W. H. Chen, J. W. Zhang, D. A. Tsai, Y. L. Cao, "A new method of manufacturing a rapid tooling with different cross-sectional cooling channels," The International Journal of Advanced Manufacturing Technology, 2017, Volume 92, Issue 9-12, Pages 3481-3487.

30. C. Kuo, M. R. Li, "Development of sheet metal forming dies with excellent mechanical properties using additive manufacturing and rapid tooling technologies," The International Journal of Advanced Manufacturing Technology, Volume 90, Issue 1, 2017, Pages 21-25.

31. Jiménez, C. López, O. Martinez-Romero, P. Mares, H. R. Siller, J. DiabbJesús, A. Sandoval-Robles, A. Elías-Zúñiga," Investigation of residual stress distribution in single point incremental forming of aluminum parts by X-ray diffraction technique," The International Journal of Advanced Manufacturing Technology, Volume 91, Issue 5-8, 2017, Pages 2571-2580.

32. Kurt, Y. Kaynak, O. S. Kamber, B. Mutlu, B. Bakir, U. Koklu," Influence of molding conditions on the shrinkage and roundness of injection molded parts," The International Journal of Advanced Manufacturing Technology, Volume 46, Issue 5-8, 2010, Pages 571-578.

33. Moayyedian, K. Abhary, R. Marian," The analysis of short shot possibility in injection molding process," The International Journal of Advanced Manufacturing Technology, Volume 91, Issue 9-12, 2017, Pages 3977-3989.

34. M. Wee, G. C. Lim, H. Y. Zheng," Dimensional analyses and surface quality of pulsed UV laser micromachining of STAVAX stainless steel mold inserts," The International Journal of Advanced Manufacturing Technology, Volume 57, Issue 9-12, 2011, Pages 1011-1027.

35. K. Behera, B. Lu, H. Ou," Characterization of shape and dimensional accuracy of incrementally formed titanium sheet parts with intermediate curvatures between two feature types," The International Journal of Advanced Manufacturing Technology, Volume 83, Issue 5-8, 2016, Pages 1099-1111.

36. Sharma,D. Datta, R. Balasubramaniam," A molecular dynamics simulation of wear mechanism of diamond tool in nanoscale cutting of copper beryllium," The International Journal of Advanced Manufacturing Technology, Volume 102, Issue 1-4, 2019,Pgaes 731-745.

37. Rahman, M.A.; Rahman, M.; Mia, M.; Asad, A.B.M.A.; Fardin, A. Manufacturing of Al Alloy Microrods by Micro Cutting in a Micromachining Center. Micromachines2019, 10, 831.

38. Lee, W.-L.; Shih, P.-J.; Hsu, C.-C.; Dai, C.-L. Fabrication and Characterization of Flexible Thermoelectric Generators Using Micromachining and Electroplating Techniques. Micromachines2019, $10,660$.

39. Zhang, Y.; Qiao, H.; Zhao, J.; Cao, Z. Research on the Mechanism of Micro-Water Jet-Guided Laser Precision Drilling in Metal Sheet. Micromachines2021, 12, 343.

40. Kuo, C.-C.; Nguyen, T.-D.; Zhu, Y.-J.; Lin, S.-X. Rapid Development of an Injection Mold with High Cooling Performance Using Molding Simulation and Rapid Tooling Technology. Micromachines2021, 12, 311.

41. Wee, L.M., Lim, G.C. \& Zheng, H.Y. Dimensional analyses and surface quality of pulsed UV laser micro-machining of STAVAX stainless steel mold inserts. Int J Adv Manuf Technol 57, 1011-1027 
(2011).

42. Hossein, H. M. Hussein, H. A. Kishawy," On the machinability of die/mold D2 steel material," he International Journal of Advanced Manufacturing Technology, Volume 85, Issue 1-4, 2016, Pages 735-740.

43. Sancaktar, E.; Bai, L. Electrically Conductive Epoxy Adhesives. Polymers2011, 3, 427-466.

44. Karnati, S., Liou, F.F. \& Newkirk, J.W. Characterization of copper-nickel alloys fabricated using laser metal deposition and blended powder feedstocks. Int J Adv Manuf Technol 103, 239-250 (2019).

45. Zhang, X.; Gao, M.; Wang, W.; Liu, B.; Li, X. Encapsulating MoO2 Nanocrystals into Flexible Carbon Nanofibers via Electrospinning for High-Performance Lithium Storage. Polymers2021, 13, 22.

46. Ahmad, H.; BinSharfan, I.I.; Khan, R.A.; Alsalme, A. 3D Nanoarchitecture of Polyaniline-MoS2 Hybrid Material for Hg(II) Adsorption Properties. Polymers2020, 12, 2731.

47. Rahmati, A. A. D. Sarhan, M. Sayuti," Investigating the optimum molybdenum disulfide (MoS2) nanolubrication parameters in CNC milling of AL6061-T6 alloy," The International Journal of Advanced Manufacturing Technology, Volume 70, Issue 5-8, 2014, Pages 1143-1155.

48. Shimoe, S.; Peng, T.-Y.; Wakabayashi, Y.; Takenaka, H.; Iwaguro, S.; Kaku, M. Laser-Milled Microslits Improve the Bonding Strength of Acrylic Resin to Zirconia Ceramics. Polymers2020, 12, 817

49. Yang, M., Li, C., Zhang, Y. et al. Effect of friction coefficient on chip thickness models in ductileregime grinding of zirconia ceramics. Int J Adv Manuf Technol 102, 2617-2632 (2019).

50. H. Zhang, D. D. Wen, Z. H. Deng, S. Li, Q. P. Wu, J. Jiang," Study on the grinding behavior of laserstructured grinding in silicon nitride ceramic," The International Journal of Advanced Manufacturing Technology, Volume 96, Issue 9-12, 2018, Pages 3081-3091.

51. Wie, J.; Kim, J. Thermal Properties of Binary Filler Hybrid Composite with Graphene Oxide and Pyrolyzed Silicon-Coated Boron Nitride. Polymers2020, 12, 2553.

52. Neumann M. Kramps Chr. Ragoß H.R. Maier K. Jahnke," Histological and microradiographic appearances of Silicon Nitride and Aluminum Oxide in a rabbit femur implantation model," Materialwissenschaft und Werkstofftechnik, Volume 35, Issue 9, 2004, Pages 569-573.

53. Cheng, W.-C.; Hsieh, Y.-T.; Liu, W.-R. Enhanced Thermal Conductivity of Silicone Composites Filled with Few-Layered Hexagonal Boron Nitride. Polymers2020, 12, 2072.

\section{Figures}




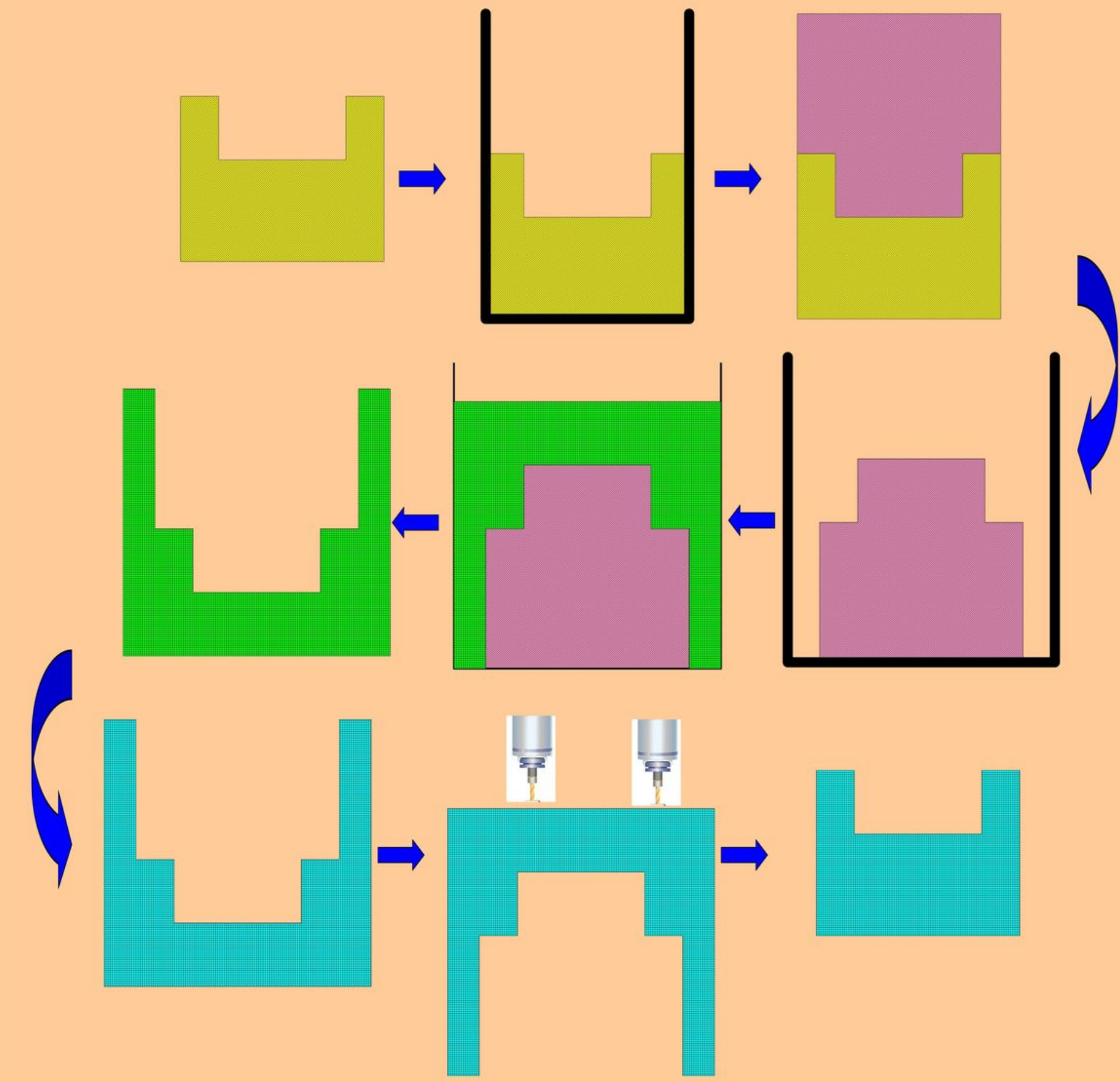

Figure 1

Process layouts for fabricating an ultra-large injection mold tooling with complex geometric conformal cooling channels 


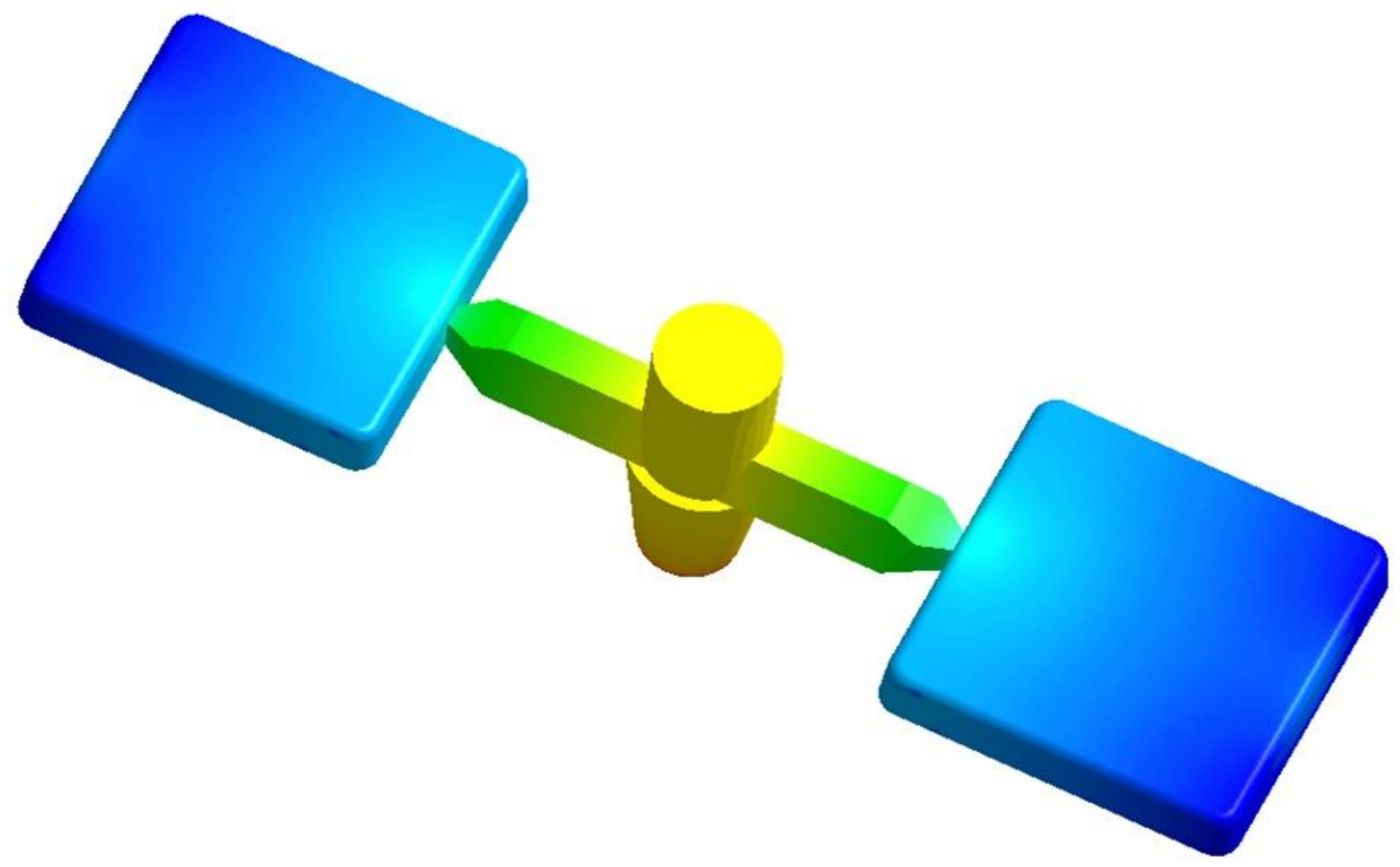

Figure 2

Schematic illustration of an injection mold with two cavities 


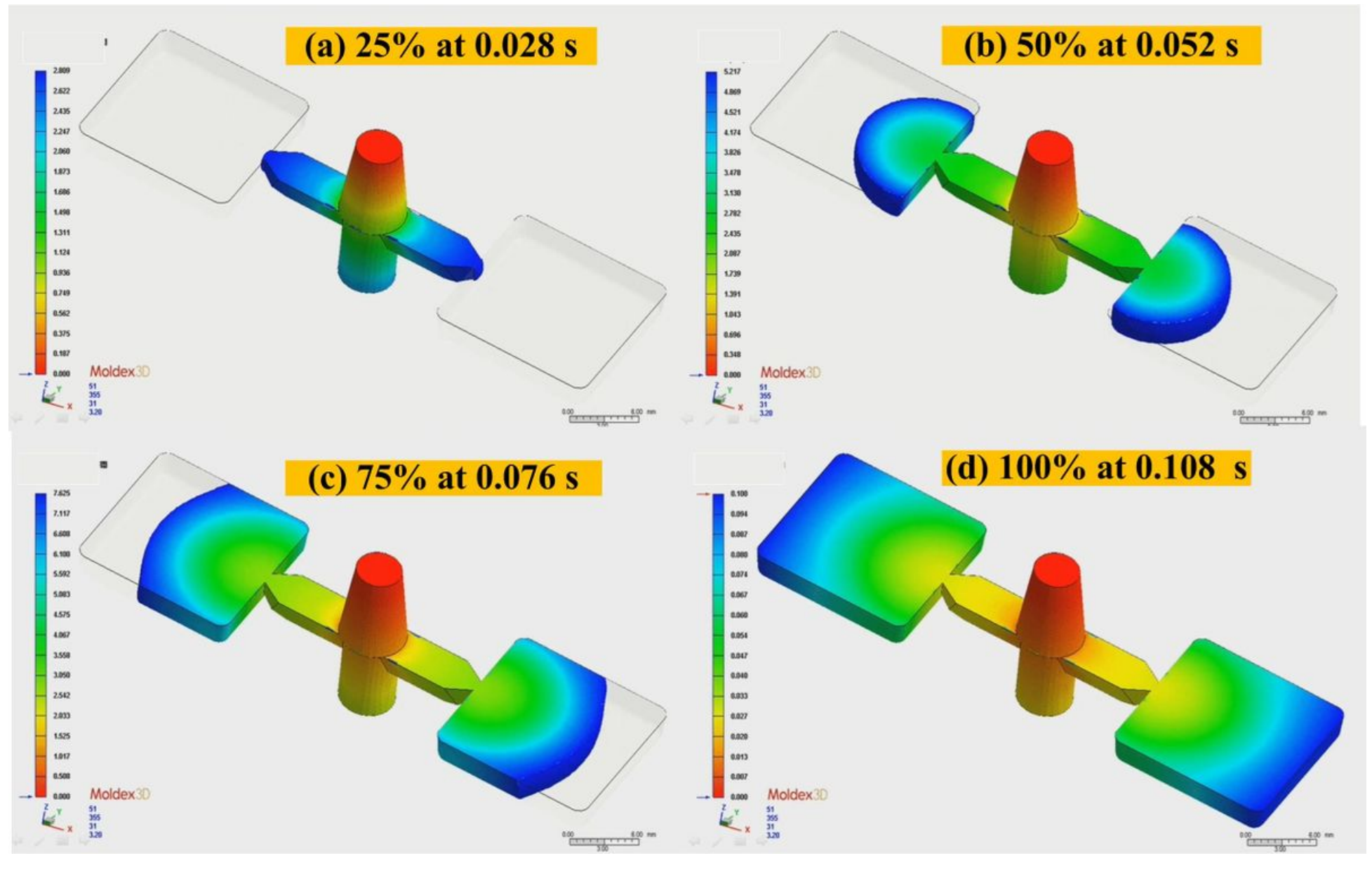

Figure 3

Simulation result of filling process 


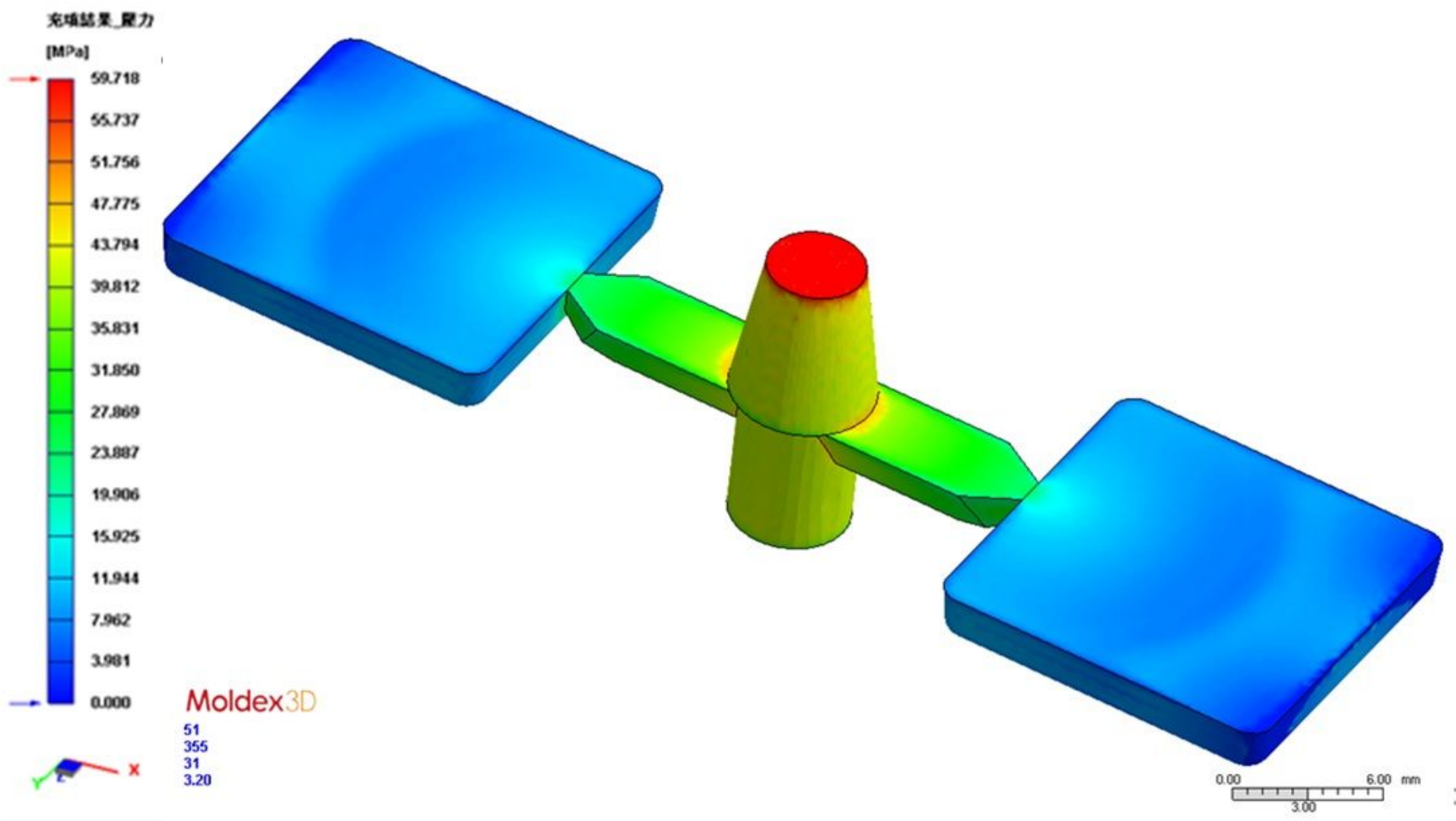

Figure 4

Simulation result of maximum injection pressure

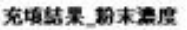

[\%]

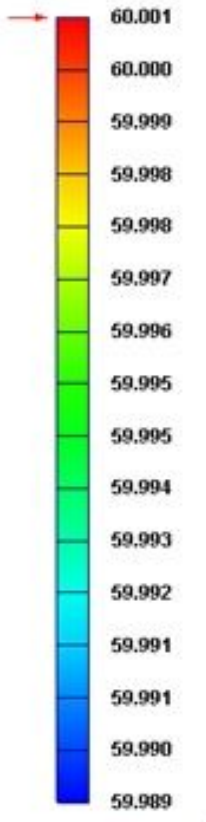

$\underbrace{X} Y \begin{array}{ll}244 \\ y & 54 \\ & 4.38\end{array}$

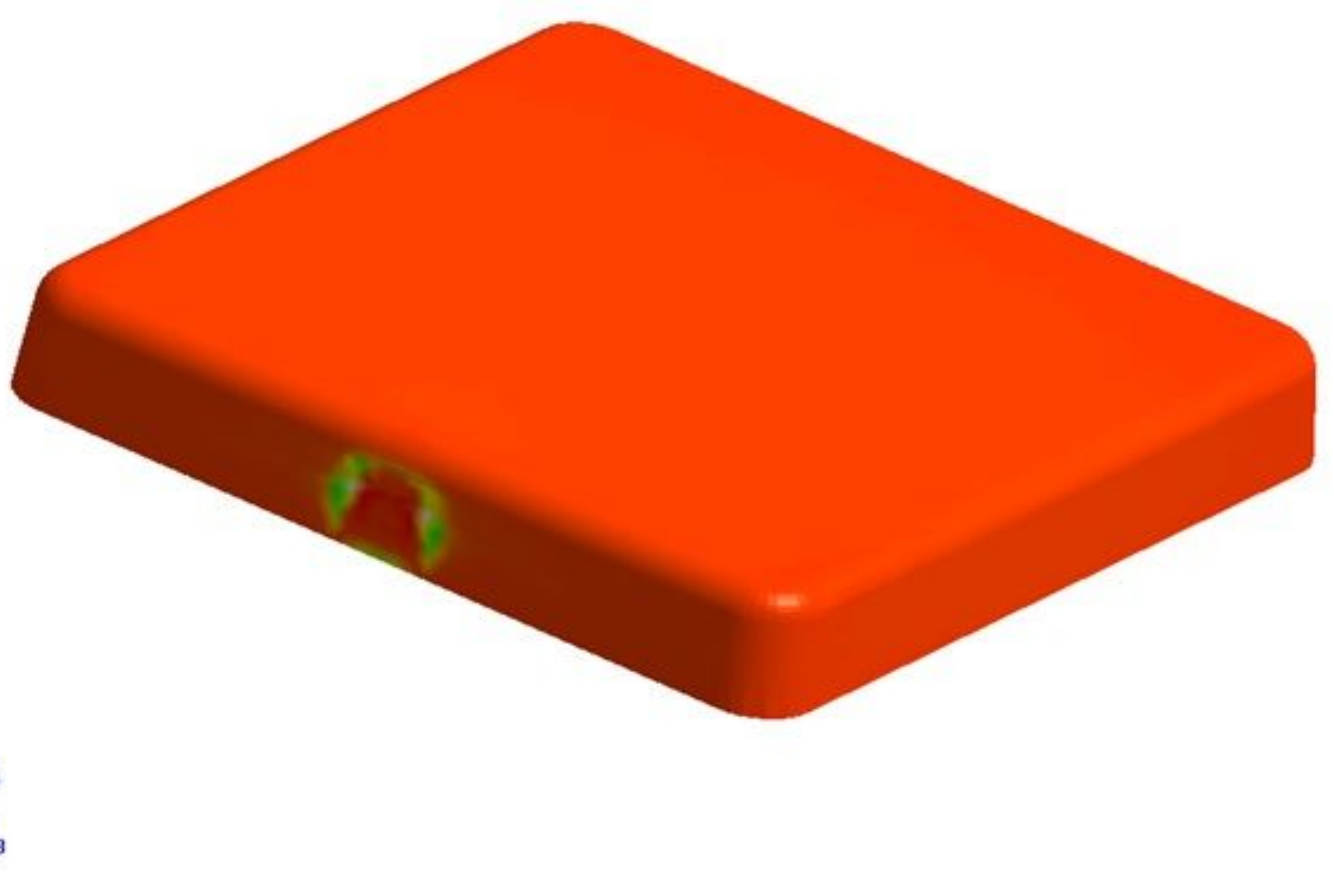


Figure 5

Simulation result of powder concentration distribution

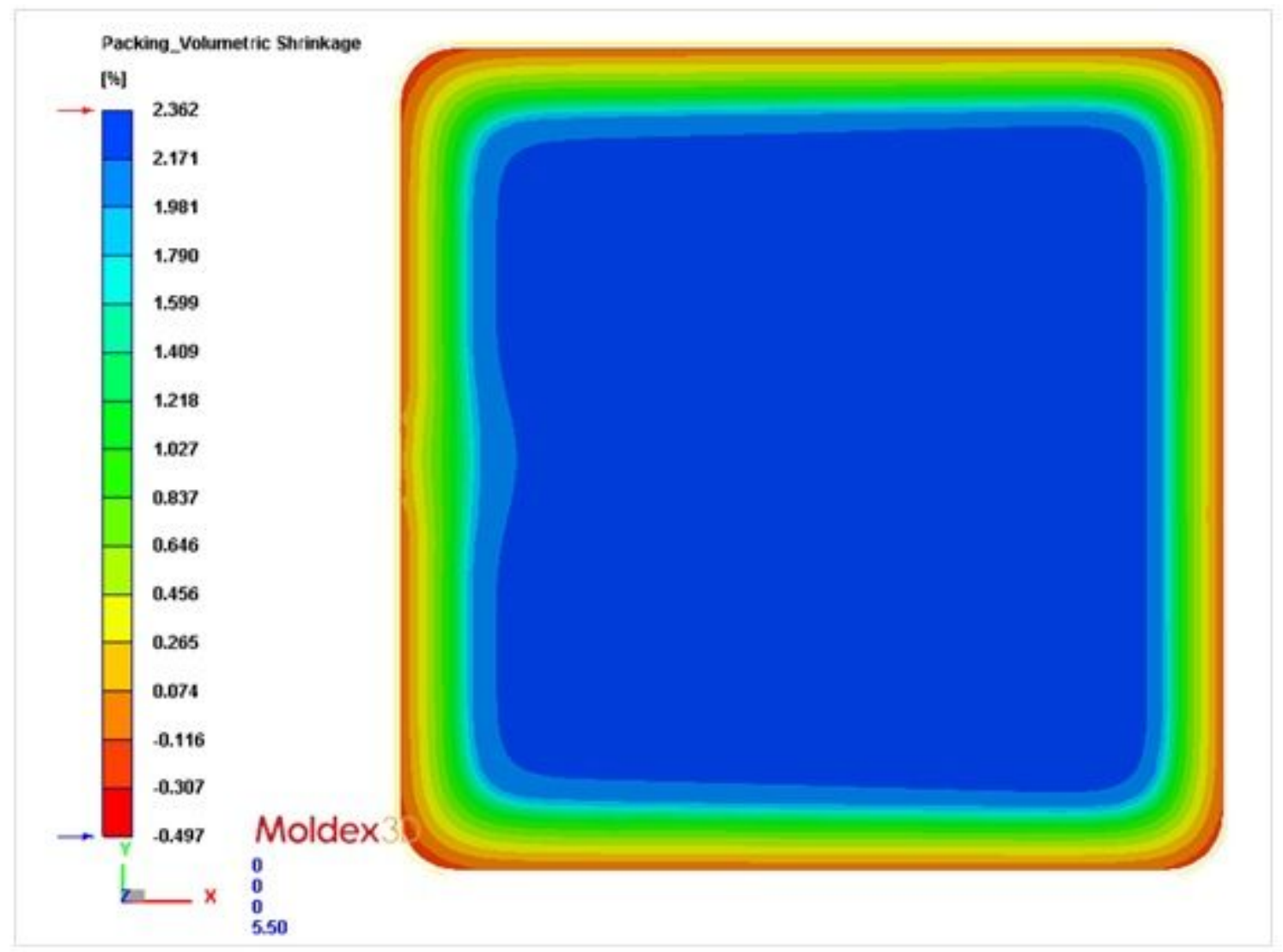

Figure 6

Simulation result of volume shrinkage 


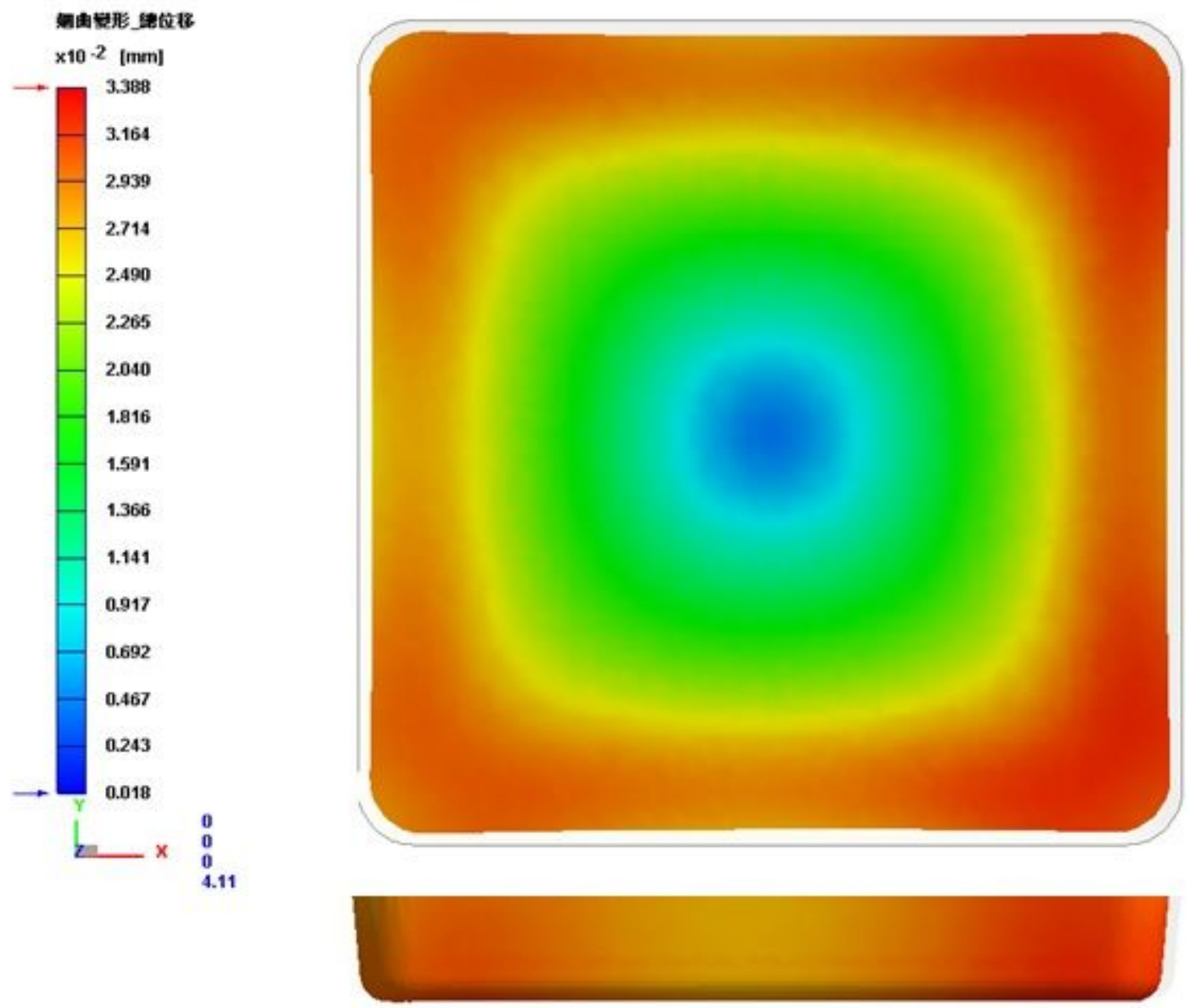

Figure 7

Simulation result of the warpage 


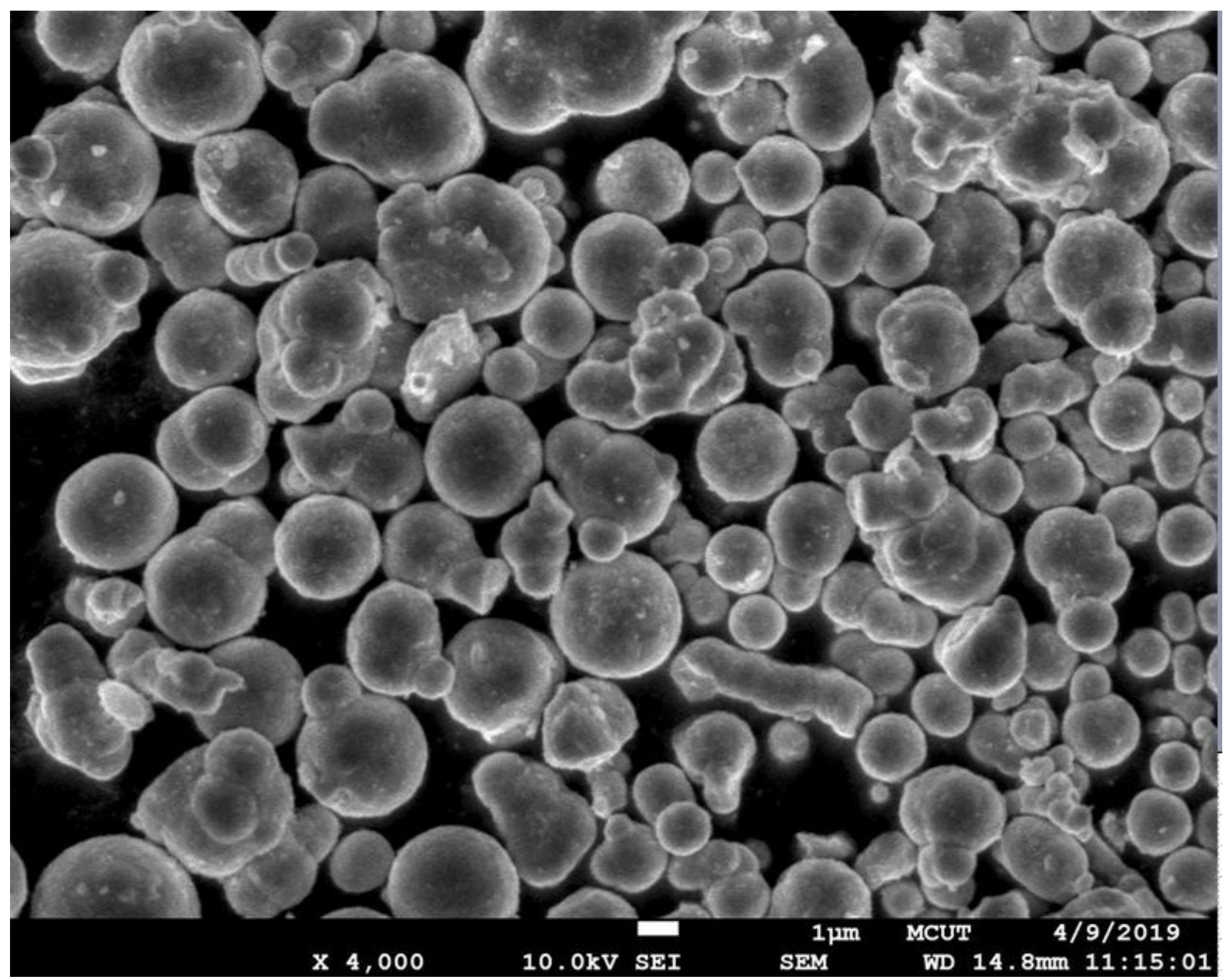

Figure 8

Morphology of the Fe powder 


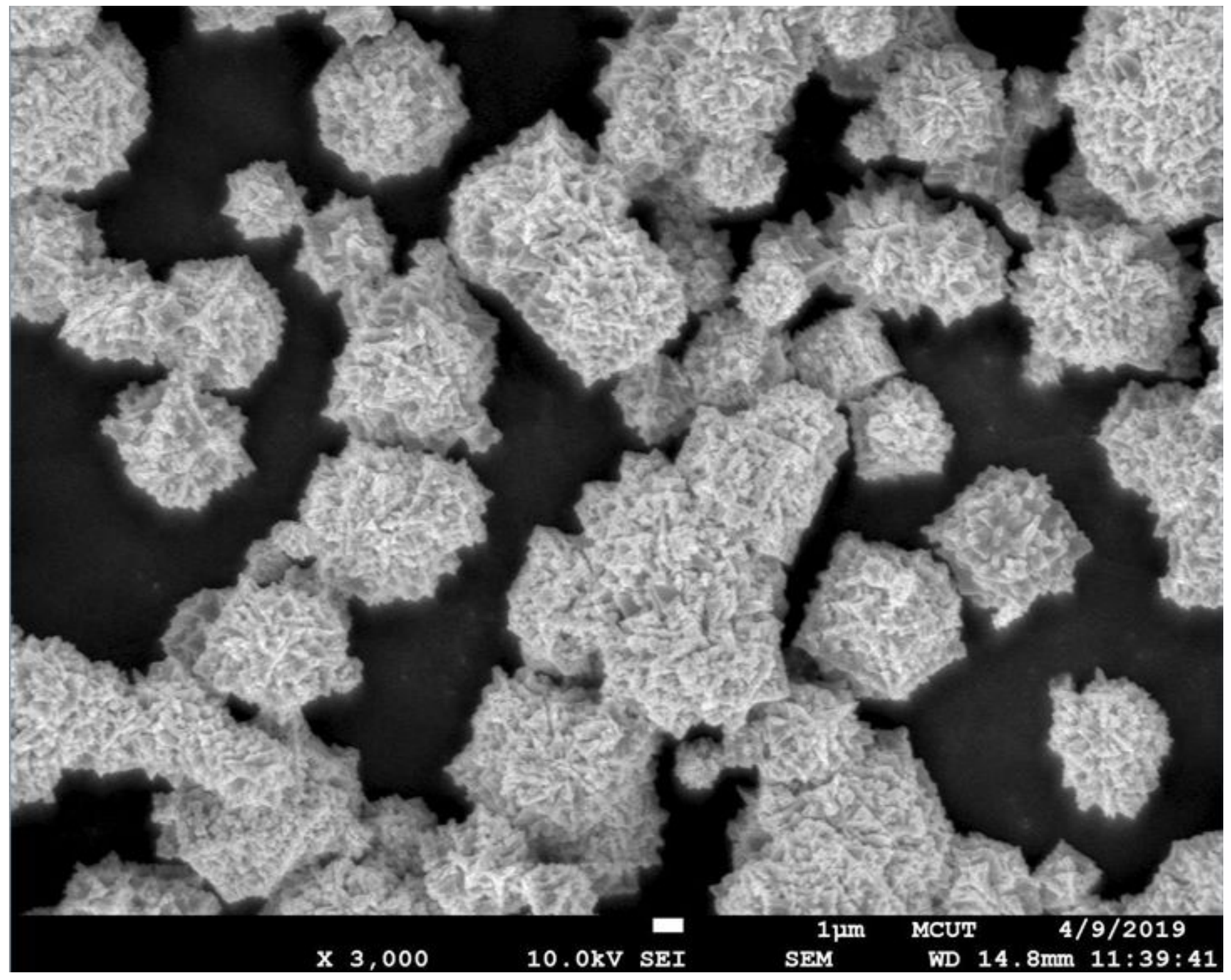

Figure 9

Morphology of the Ni powder 


\section{1}

$0.0685 \mathrm{~s}$

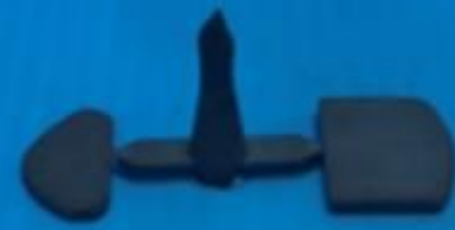

$0.116 \mathrm{~s}$
$0.0805 \mathrm{~s}$

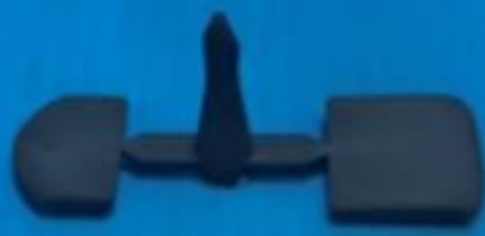

$0.128 \mathrm{~s}$

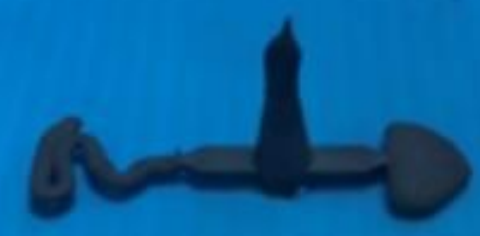

$0.092 \mathrm{~s}$

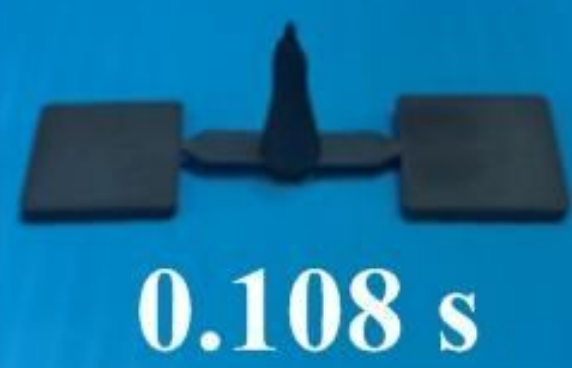

Figure 10

Results of the short shot test

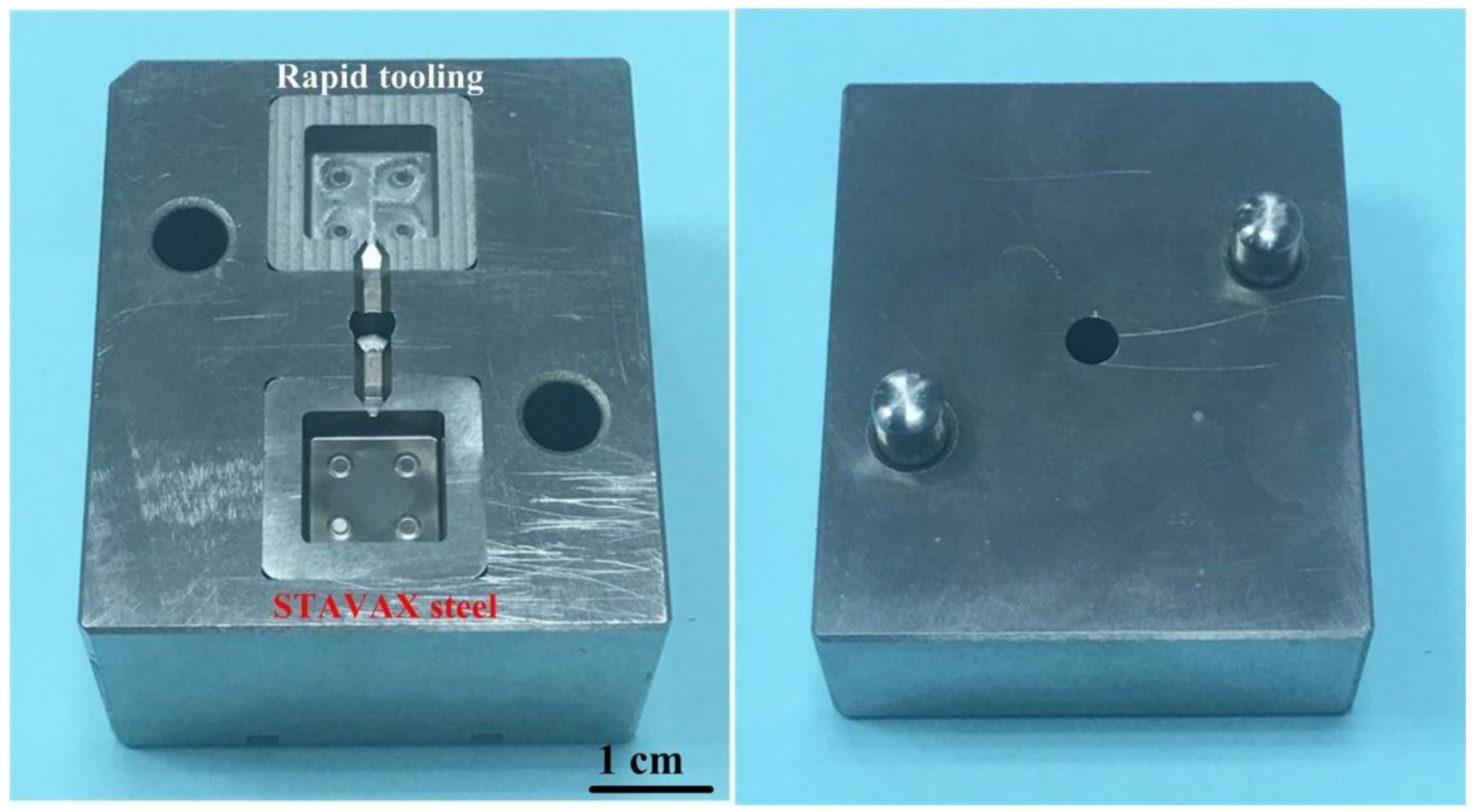

Figure 11 
Injection molds fabricated by rapid tooling and STAVAX steel
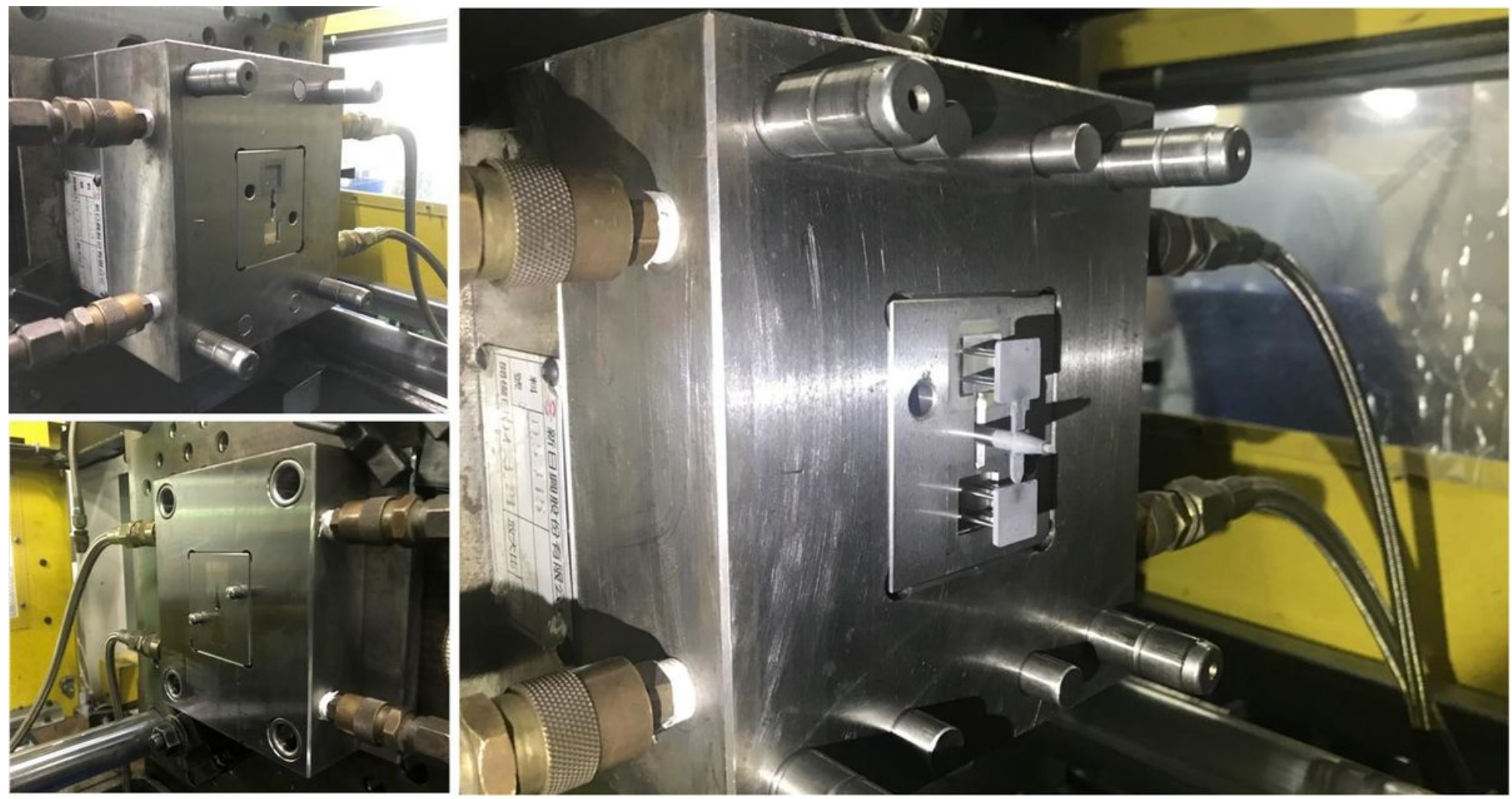

Figure 12

A green part was ejected during MIM process

(a)

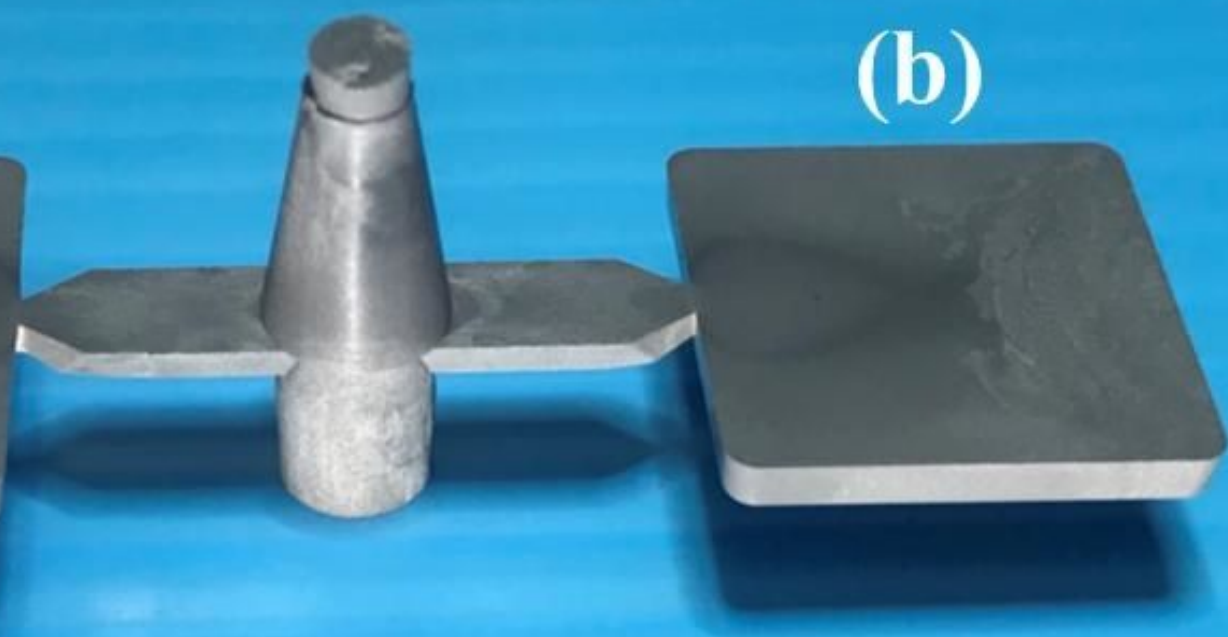

Figure 13 
In order to evaluate the longevity of injection molds made by STAVAX stainless steel [33] and Al-filled epoxy resins, the MIM process was carried out with feedstock of Fe2Ni. Figure 14 shows the average surface roughness of mold surface as a function of injection molding cycles. Figure 15 shows the average surface roughness of the injection mold fabricated by STAVAX stainless steel after 1 to 2500 injection molding cycles. As can be seen, the average surface roughness of mold fabricated by STAVAX stainless steel after $1,500,900,1300,1600,2500$, and 2700 molding cycles were $148 \mathrm{~nm}, 168 \mathrm{~nm}, 156$ $\mathrm{nm}, 160 \mathrm{~nm}, 147 \mathrm{~nm}, 212 \mathrm{~nm}$, and $143 \mathrm{~nm}$, respectively. Figure 16 shows the average surface roughness of the injection mold fabricated by Al-filled epoxy resins after 1 to 2500 injection molding cycles. The average surface roughness of the injection mold fabricated by Al-filled epoxy resins after 1, 500, 900, 1300, 1600, 2500, and 2700 molding cycles were $174 \mathrm{~nm}, 161 \mathrm{~nm}, 175 \mathrm{~nm}, 158 \mathrm{~nm}, 219 \mathrm{~nm}, 227 \mathrm{~nm}$, and $220 \mathrm{~nm}$, respectively. The results clearly show that the changes in the average surface roughness of the injection mold fabricated by Al-filled epoxy resins before 1300 molding cycles is very close to that of the injection mold fabricated by STAVAX stainless steel. However, the average surface roughness of the injection mold fabricated by Al-filled epoxy resins increased with increasing the injection mold cycles after 1300 molding cycles.

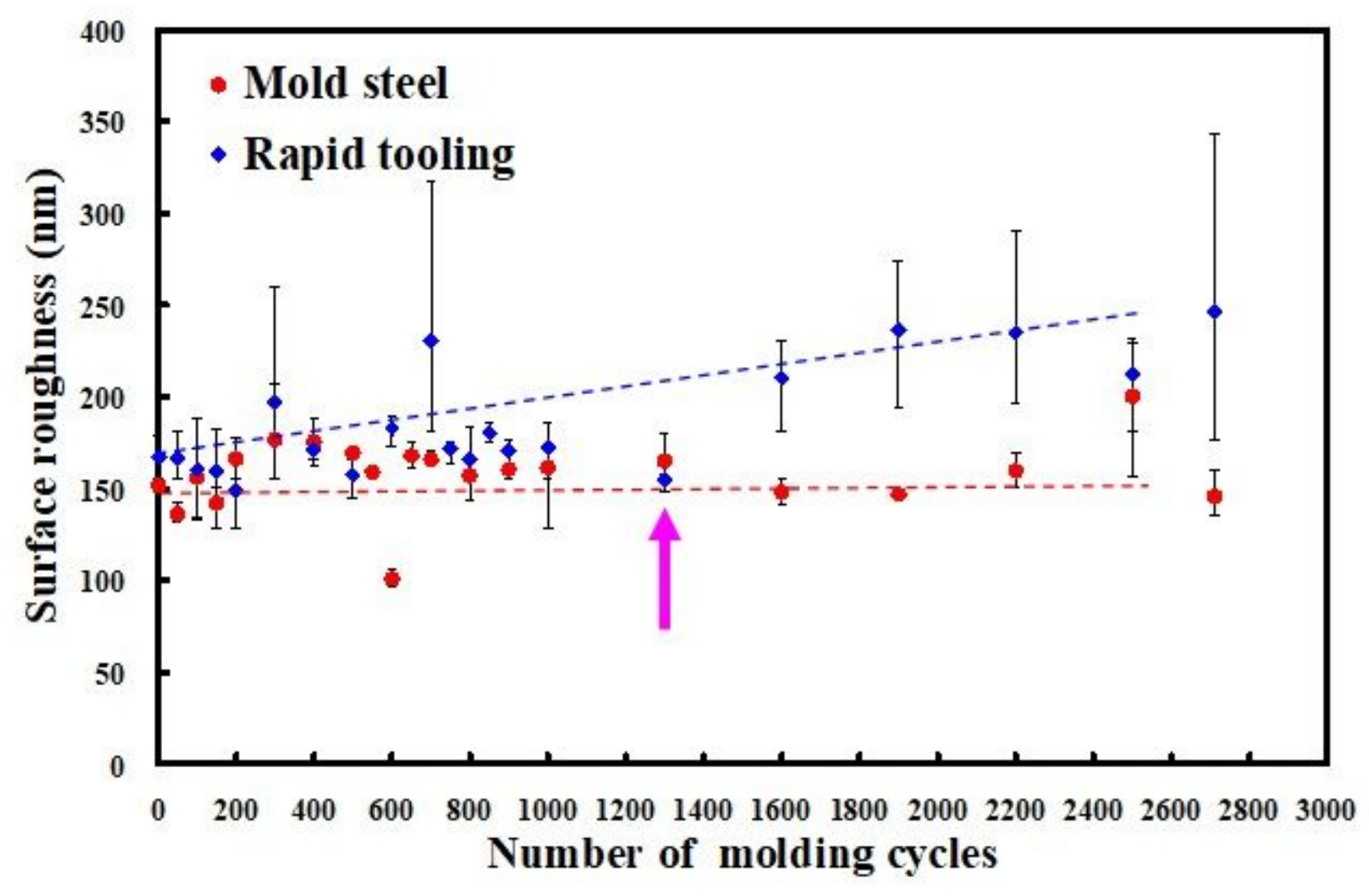

Figure 14

Average surface roughness of mold surface as a function of injection molding cycles 


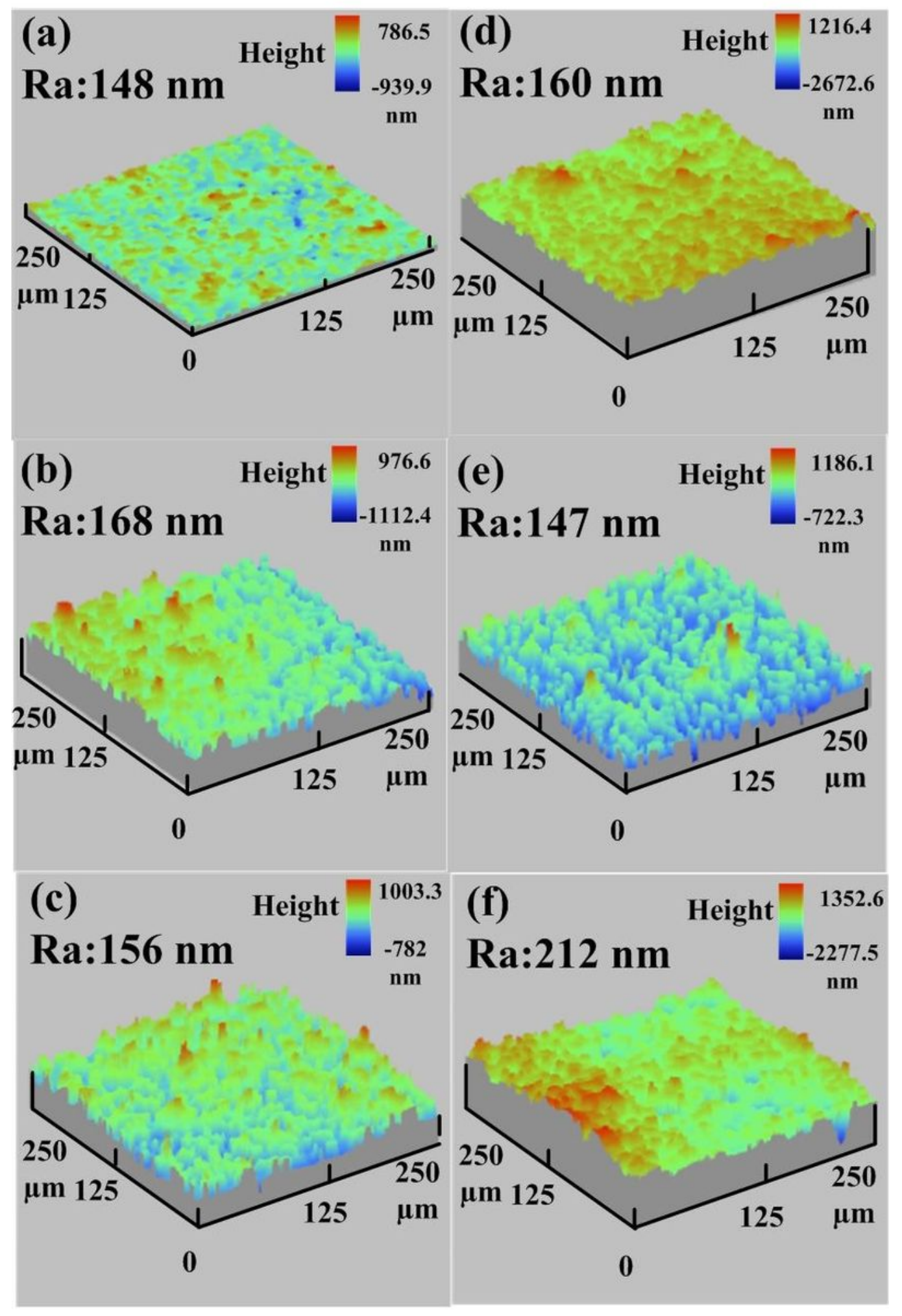

Figure 15

Average surface roughness of the injection mold fabricated by STAVAX stainless steel after injection molding cycles of (a) 1, (b) 500, (c) 900, (d) 1300, (e) 1600, and (f) 2500 


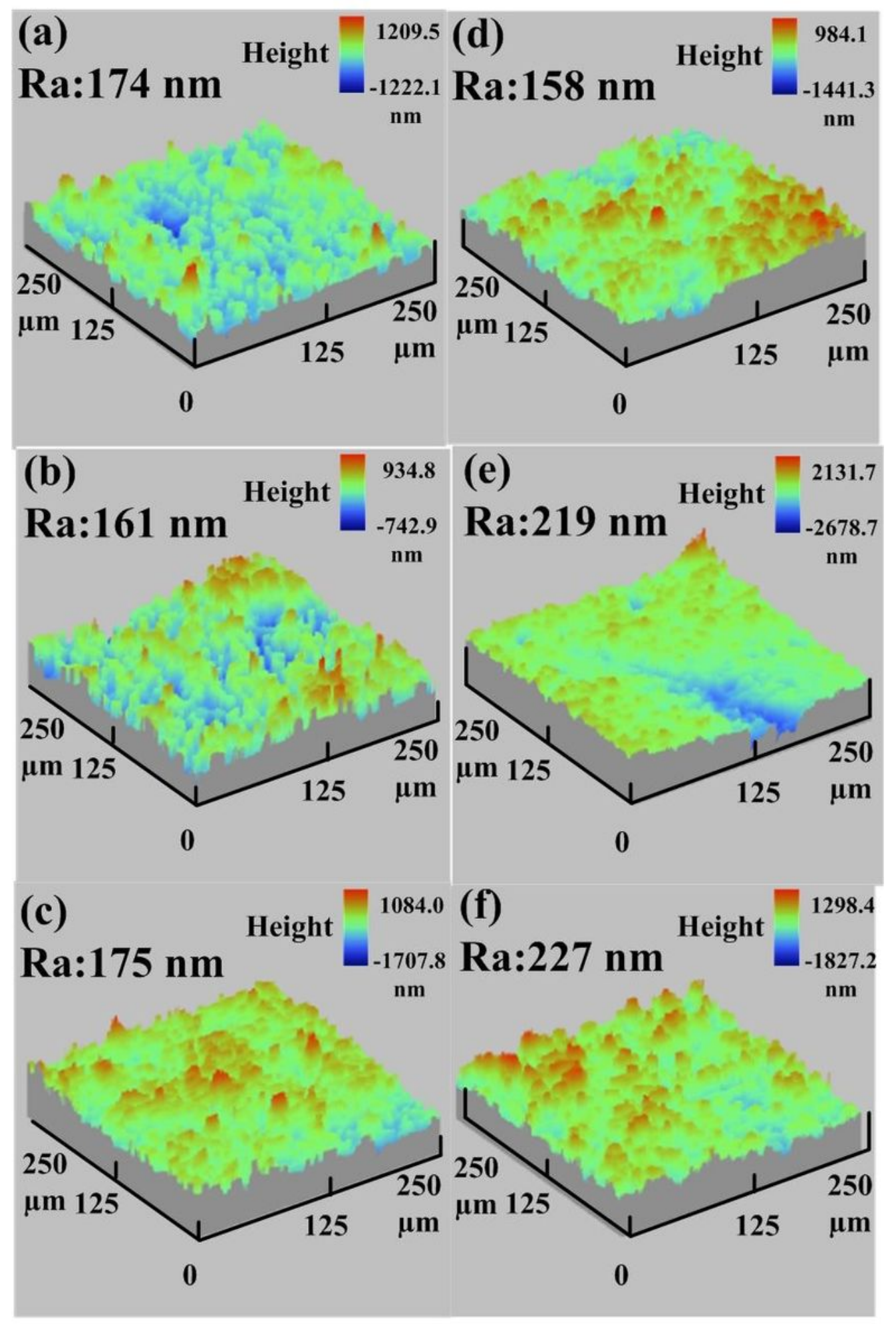

Figure 16

Average surface roughness of the injection mold fabricated by Al-filled epoxy resins after injection molding cycles of (a) 1, (b) 500, (c) 900, (d) 1300, (e) 1600, and (f) 2500 


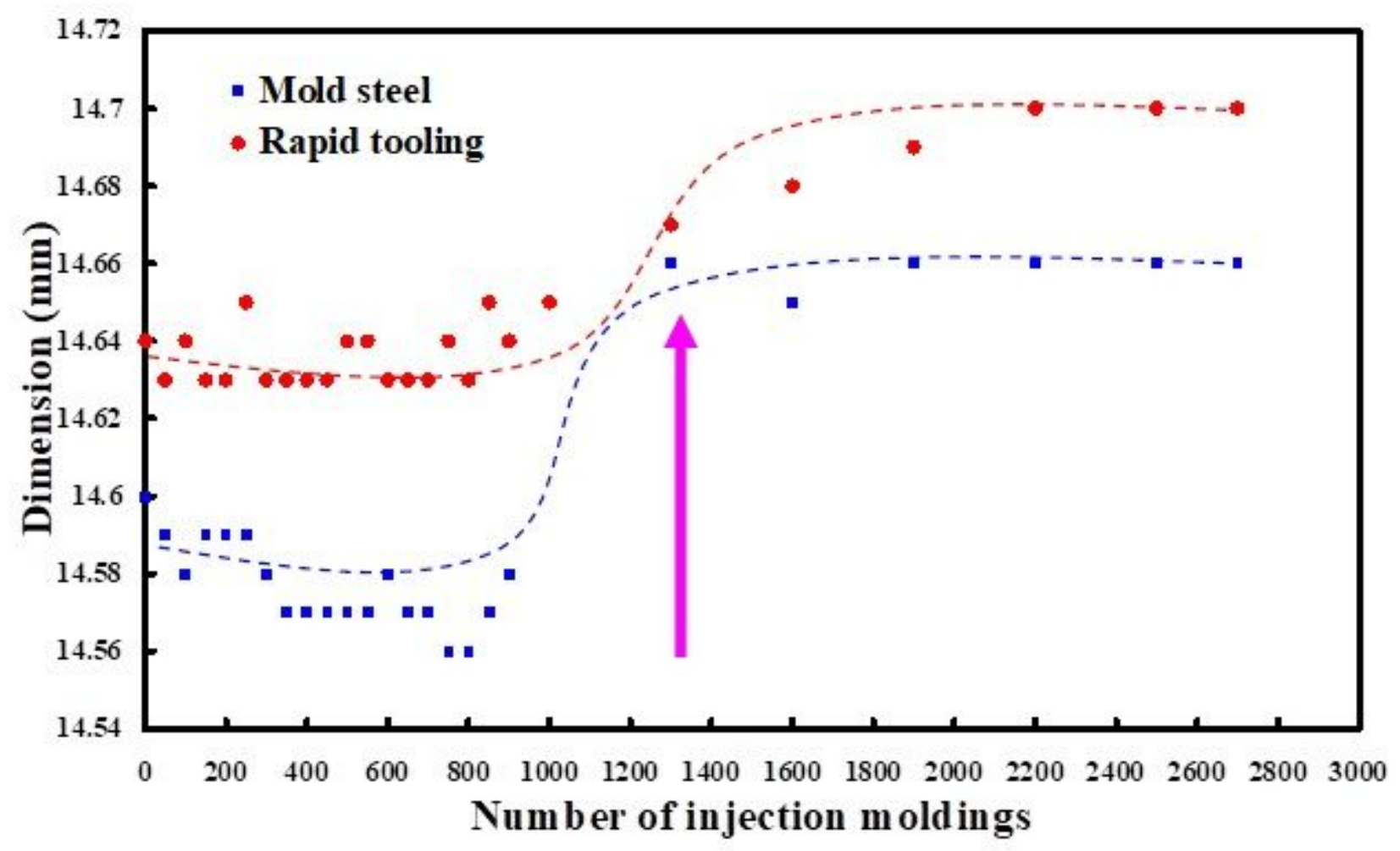

Figure 17

Dimension of the green part as a function of injection molding cycles

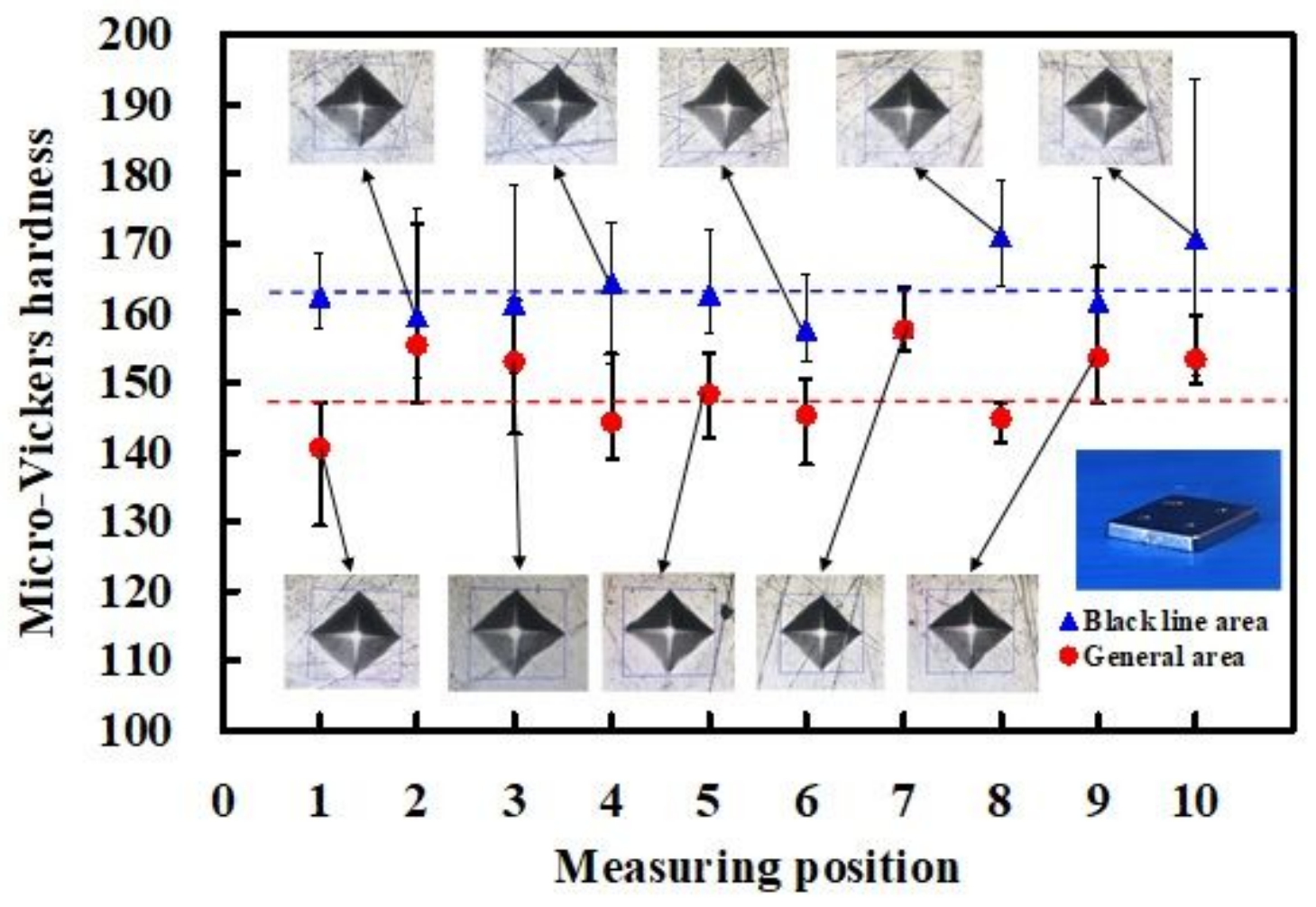

Figure 18 
Micro-Vickers hardness of black-line area and general area in the sintered part

\section{Green part \\ Sintered part}

\section{$10 \mathrm{~mm}$}

Figure 19

Results of green part and sintered product

\section{Green part}
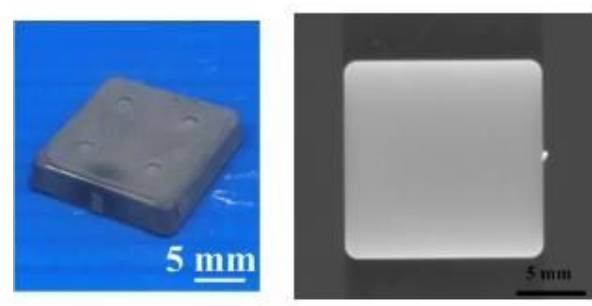

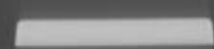

Sintered product

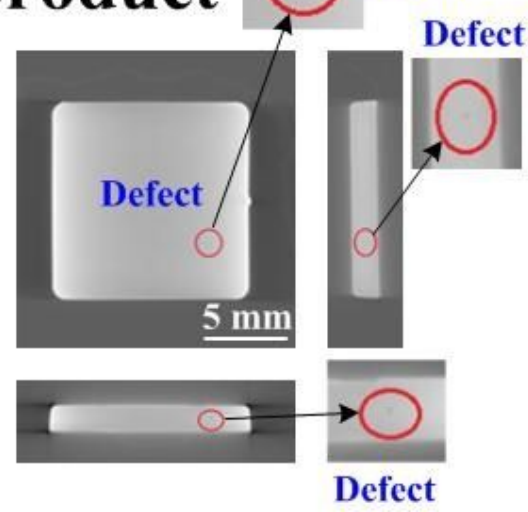

\section{- Defect}

$5 \mathrm{~mm}$

Figure 20

X-ray analysis of the green part and sintered product

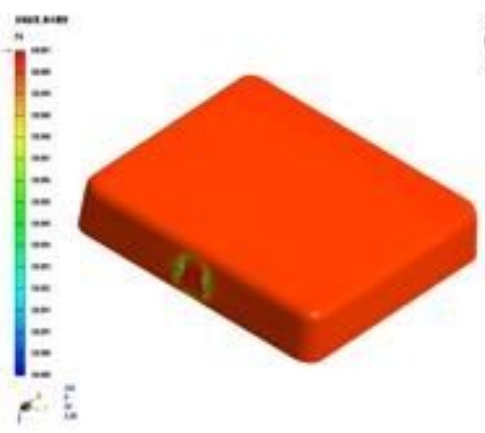

(a)

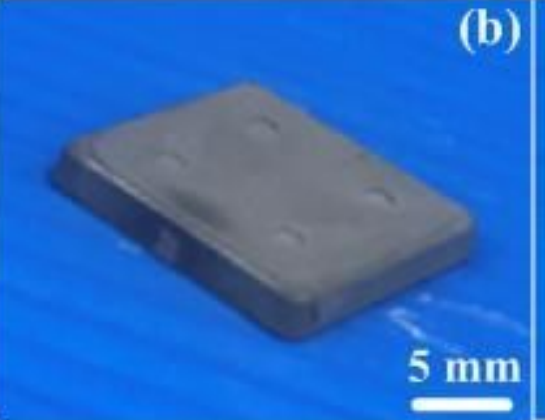

(c) 
Figure 21

Black-line position in (a) simulation result, (b) green part, and (c) sintered part
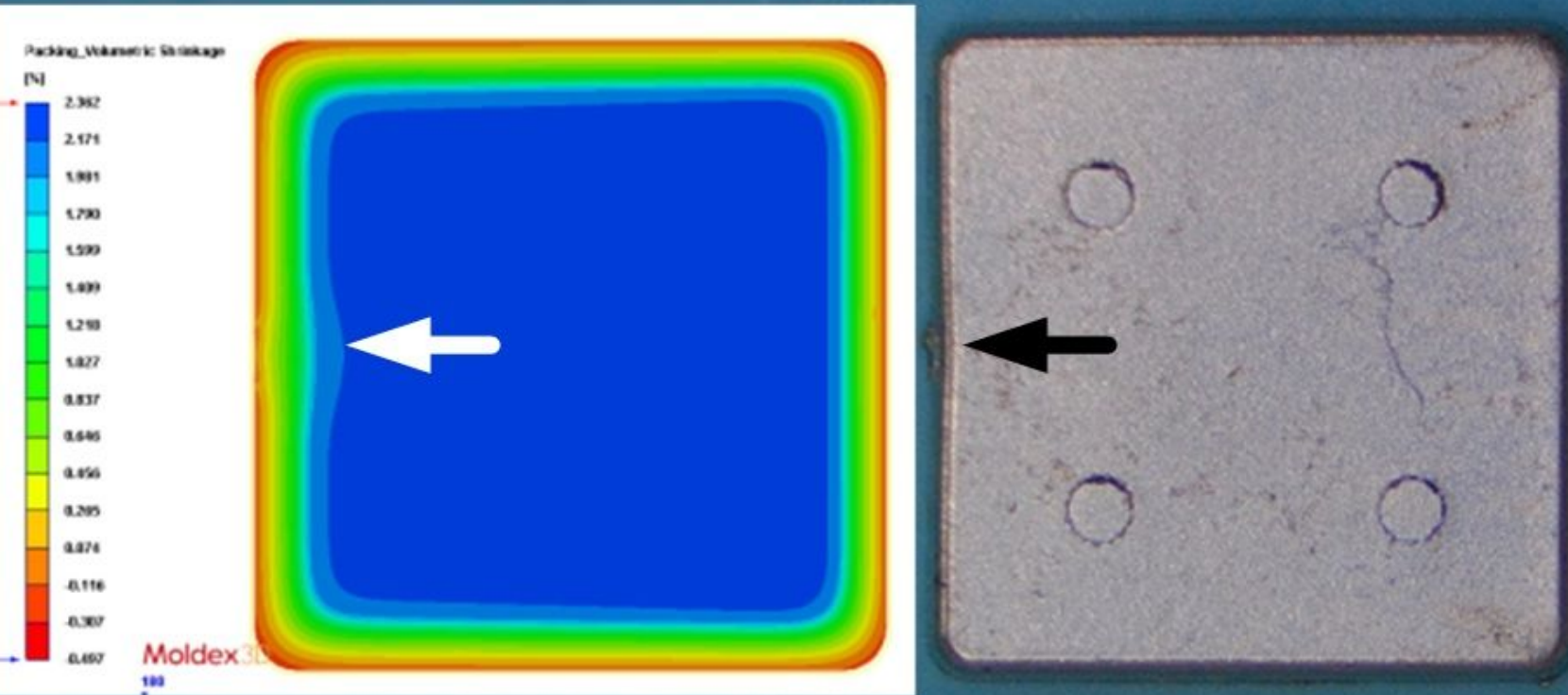

Figure 22

Volumetric shrinkage in (a) simulation result and (b) green part

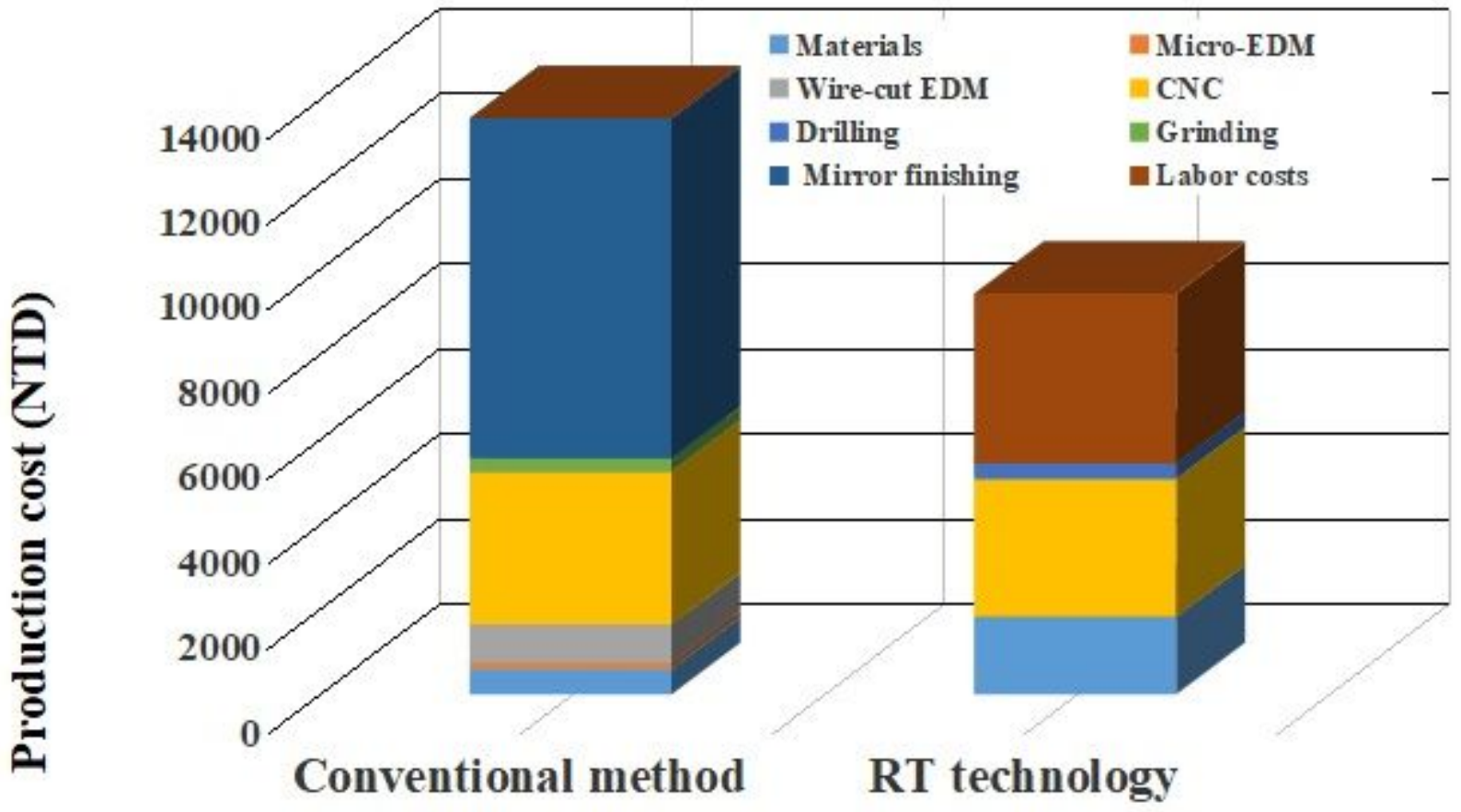


Figure 23

Production cost of the molds fabricated by conventional method and RT technology

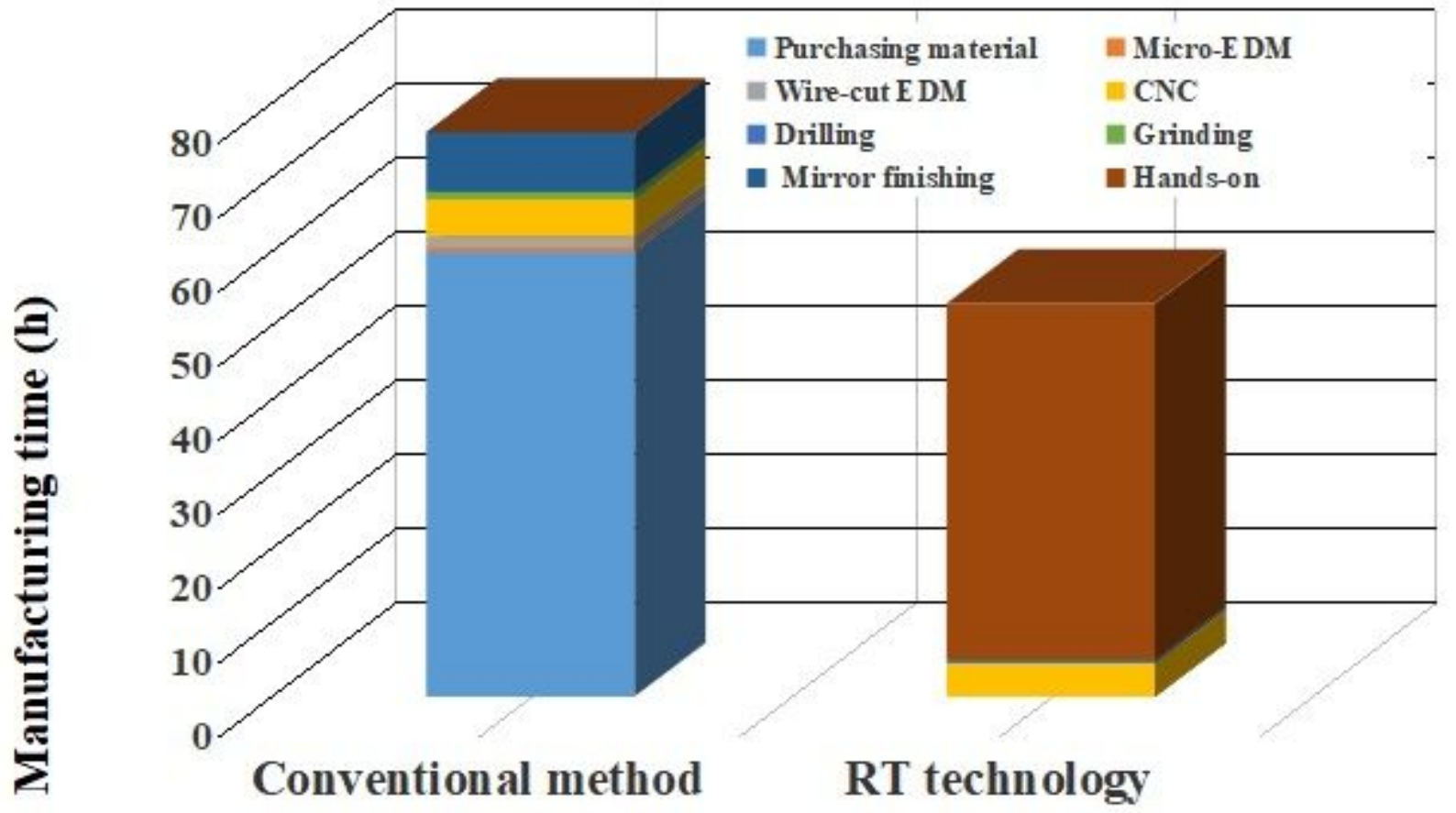

Figure 24

Manufacturing time of the molds fabricated by conventional method and RT technology 